RECEIVED

APR 081998

ORNL/GWPO-027

\title{
Environmental Sciences Division Groundwater Program Office Report for Fiscal Years 1995-1997
}

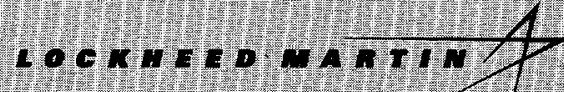

\author{
D. D. Huff \\ Environmental Sciences Division \\ Publication No. 4751
}

\section{MASTER}

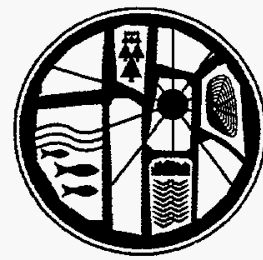

MANAGED ANO OPERATED BY LOCKHEED MARTN ENERGY RESEARCH CORPORATION FOA THE UNITED STATES DEPABTMENT OF ENERGY 
This report has been reproduced directly from the best available copy.

Available to DOE and DOE contractors from the Office of Scientific and Technical Information, P.O. Box 62. Oak Ridge. TN 37831; prices available from (615) 576-8401, FTS 626-8401.

Available to the public from the National Technical information Service, U.S. Department of Commerce, 5285 Port Royal Rd., Springfield, VA 22161.

This report was prepared as an account of work sponsored by an agency of the United States Government. Neither the United States Government nor any agency thereof, nor any of their employees, makes any warranty, express or implied, or assumes any legal liability or responsibility for the accuracy, completeness, or usefulness of any information, apparatus, product, or process disclosed, or represents that its use would not infringe privately owned rights. Reference herein to any specific commercial product, process, or service by trade neme, trademark, manufacturer, or otherwise. does not necessarily constitute or imply its endorsement, recommendation, or favoring by the United States Government or any agency thereof. The views and opinions of authors expressed herein do not necessarily state or reflect those of the United States Government or any agency thereof. 


\section{DISCLAIMER}

Portions of this document may be illegible electronic image products. Images are produced from the best available original document. 


\title{
ENVIRONMENTAL SCIENCES DIVISION \\ GROUNDWATER PROGRAM OFFICE \\ REPORT FOR FISCAL YEARS 1995-1997
}

\author{
Compiled by \\ D.D. Huff \\ with contributions from \\ D.D. Huff \\ G.R. Moline \\ L.E. Toran \\ A.J. Stewart \\ R.B. Clapp \\ C.T. Rightmire \\ Date Issued — March, 1998 \\ Prepared by the \\ Environmental Sciences Division \\ Oak Ridge National Laboratory \\ ESD Publication Number 4751 \\ OAK RIDGE NATIONAL LABORATORY \\ Oak Ridge, Tennessee 37831-6285 \\ managed by \\ LOCKHEED MARTIN ENERGY RESEARCH, CORP. \\ for the \\ U.S. Department of Energy \\ under contract DE-AC05-96OR22464
}




\section{CONTENTS}

\section{Page}

CONTENTS $\ldots \ldots \ldots \ldots \ldots \ldots \ldots \ldots \ldots \ldots \ldots \ldots \ldots \ldots \ldots \ldots \ldots \ldots \ldots \ldots$

FIGURES $\ldots \ldots \ldots \ldots \ldots \ldots \ldots \ldots \ldots \ldots \ldots \ldots \ldots \ldots \ldots \ldots \ldots \ldots \ldots \ldots \ldots$

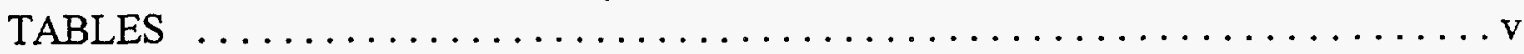

ABBREVIATIONS $\ldots \ldots \ldots \ldots \ldots \ldots \ldots \ldots \ldots \ldots \ldots \ldots \ldots \ldots \ldots \ldots \ldots$

EXECUTIVE SUMMARY $\ldots \ldots \ldots \ldots \ldots \ldots \ldots \ldots \ldots \ldots \ldots \ldots$ vii

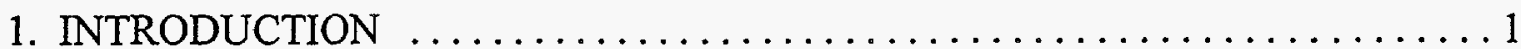

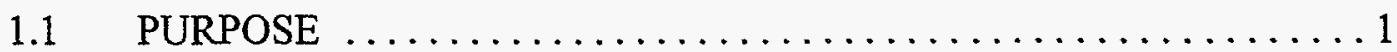

1.2 GWPO ADVISORY COMMITTEE REVIEWS AND COMMENTS . . 2

2. CONCEPTUAL HYDROLOGIC FRAMEWORK $\ldots \ldots \ldots \ldots \ldots \ldots \ldots \ldots$

2.1 HYDROLOGIC FRAMEWORK FOR THE OAK RIDGE RESERVATION: SUMMARY OF KEY ELEMENTS .......... 3

2.2 REVISIONS AND UPDATES TO THE CONCEPTUAL MODEL . . .5

3. DATA CAPTURE AND DOCUMENTATION $\ldots \ldots \ldots \ldots \ldots \ldots \ldots \ldots \ldots$

$3.1 \quad$ USGS TRITIUM TRACER TEST $\ldots \ldots \ldots \ldots \ldots \ldots \ldots \ldots \ldots \ldots$

3.2 NOBLE GAS TRACER TEST DATA SETS $\ldots \ldots \ldots \ldots \ldots \ldots \ldots 7$

3.3 SAMPLING PROTOCOL TEST DATA SETS $\ldots \ldots \ldots \ldots \ldots \ldots$.

4. GEOLOGY AND GROUNDWATER FLOW $\ldots \ldots \ldots \ldots \ldots \ldots$

4.1 PRELIMINARY KARST INVENTORY $\ldots \ldots \ldots \ldots \ldots \ldots \ldots$

4.2 POROSITY OF MUDROCKS $\ldots \ldots \ldots \ldots \ldots \ldots \ldots \ldots \ldots \ldots \ldots$

5. MODELING FLOW IN FRACTURED ROCK SYSTEMS $\ldots \ldots \ldots \ldots \ldots \ldots 13$

5.1 WATER BALANCE MODELING $\ldots \ldots \ldots \ldots \ldots \ldots \ldots \ldots \ldots$

5.2 FRACTURE FLOW VERSUS EQUIVALENT POROUS MEDIA MODELS ................................. 14

5.2.1 Tritium Tracer Test Modeling .................. 14

5.2.2 Modeling the Bear Creek Valley Helium Tracer Test . . . . . . . 15

5.3 VARIABLE DENSITY AND MULTIPHASE MODELING $\ldots \ldots \ldots 18$

5.3.1 Multiphase code evaluation .................... 18

5.3.2 Variable density model of the S3 Ponds nitrate plume ...... 18

5.3 .3 Summary .............................. 19 


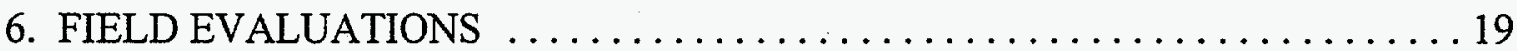

6.1 WEST BEAR CREEK VALLEY NOBLE GAS TRACER TEST . . . 19

6.2 SAMPLING PROTOCOLS FOR FRACTURED MEDIA $\ldots \ldots \ldots 20$

6.2 .1 Scope and Objectives .......................... 20

6.2 .2 Approach ................................21

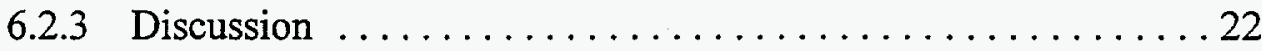

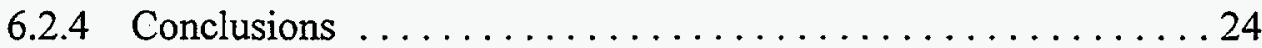

6.3 MELTON VALLEY HYDROGRAPH ANALYSIS PROJECT $\ldots \ldots 25$

6.3.1 Scope and Objectives ......................... 25

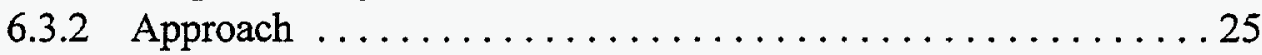

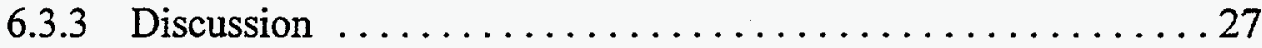

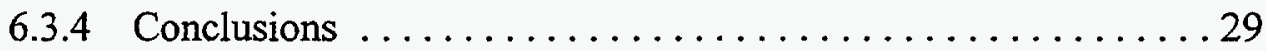

6.4 DEEP GW FLOW SYSTEM EVALUATION $\ldots \ldots \ldots \ldots \ldots \ldots 29$

7. REMEDIATION TECHNOLOGY ............................ 32

7.1 CONSTRUCTED WETLAND DEMONSTRATION STUDY $\ldots \ldots .32$

7.2 PARTICIPATION IN WAG4 LOW-PRESSURE PERMEATION

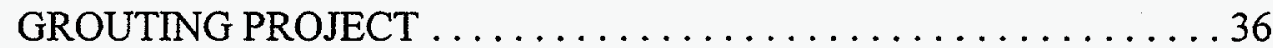

7.3 ENVIRONMENTAL DECISION ANALYSIS . . . . . . . . . 37

8. GWPO SITE SUPPORT AND INTERACTIONS $\ldots \ldots \ldots \ldots \ldots \ldots \ldots \ldots . \ldots 40$

$8.1 \quad$ ALL SITES ............................... 40

8.2 OAK RIDGE RESERVATION SITES $\ldots \ldots \ldots \ldots \ldots \ldots \ldots \ldots . \ldots \ldots$

8.3 EAST TENNESSEE TECHNOLOGY PARK $\ldots \ldots \ldots \ldots \ldots \ldots 41$

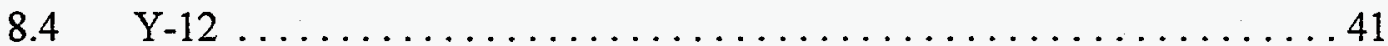

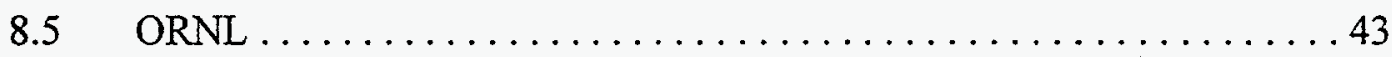

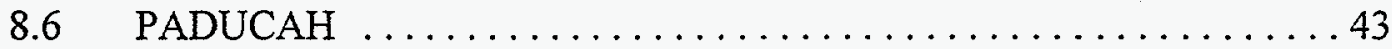

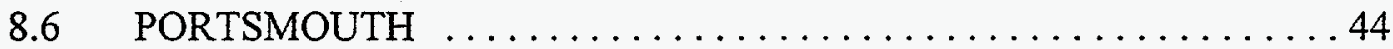

9. COMBINATION OF R\&D AND SITE NEEDS $\ldots \ldots \ldots \ldots \ldots \ldots \ldots \ldots . \ldots \ldots$

9.1 DENSE NON-AQUEOUS PHASE LIQUID (DNAPL) CONTAMINATION ...........................45

9.2 THE IMPORTANCE OF KARST (CARBONATE ROCK) FEATURES ON THE ORR .......................46

9.3 BACKGROUND WATER CHEMISTRY $\ldots \ldots \ldots \ldots \ldots \ldots \ldots . \ldots 47$

9.4 SAMPLING PROTOCOL $\ldots \ldots \ldots \ldots \ldots \ldots \ldots \ldots \ldots \ldots$

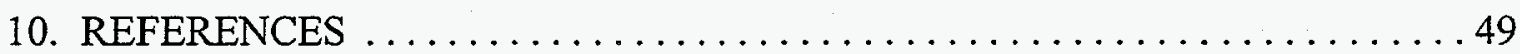

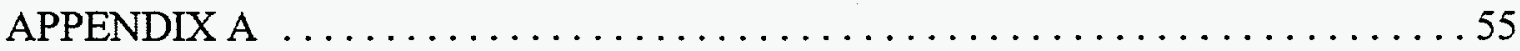




\section{FIGURES}

Figure

Page

1. Schematic of some various geologic factors that influence flow below the water table in dipping carbonates $\ldots \ldots \ldots \ldots \ldots \ldots \ldots \ldots \ldots \ldots \ldots$

2. Calculated interval effective porosity as a function of depth. Porosities are based on helium porosimetry.

3. USGS tritium tracer experiment site and distribution of wells and tritium

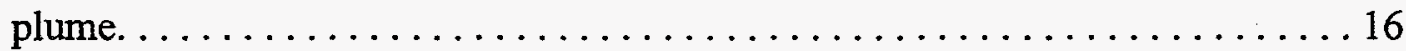

4. Tritium breakthrough with time: modeled and measured. . . . . . . . . 17

5. The wetland prototype during construction, prior to installation of

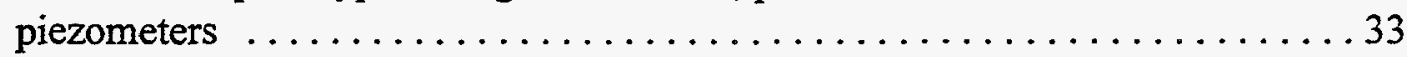

6. Decision analysis evaluation of the break-even point between grouting or cap, collect and treat options at WAG $4 \ldots \ldots \ldots \ldots \ldots \ldots \ldots \ldots \ldots \ldots$ 


\section{TABLES}

Table

Page

1. Water temperature in piezometers located in the upstream and downstream halves of a $20-\mathrm{m}$ long constructed wetland . . . . . . . . 34 


\begin{tabular}{ll} 
& \multicolumn{1}{c}{ ABBREVIATIONS } \\
& \\
& \\
CERCLA & Comprehensive Environmental Restoration, Compensation and \\
& Liability Act \\
DOE & U.S. Department of Energy \\
DOE-OR & U.S. Department of Energy Oak Ridge Site Office \\
EPA & U.S. Environmental Protection Agency \\
ER & Environmental Restoration \\
FY & Fiscal Year \\
GWPO & Groundwater Program Office \\
GWPP & Groundwater Protection Program \\
IAG & Interagency Agreement \\
IRM & Interim Remedial Measure \\
MMES & Martin Marietta Energy System \\
OREIS & Oak Ridge Environmental Information System \\
ORHSP & Oak Ridge Hydrology Support Program \\
ORNL & Oak Ridge National Laboratory \\
ORR & Oak Ridge Reservation \\
ORRHAGS & Oak Ridge Reservation Hydrology and Geology Studies \\
PGDP & Paducah Gaseous Diffusion Plant \\
PORTS & Portsmouth Gaseous Diffusion Plant \\
RCRA & Resource Conservation and Recovery Act \\
RMO & Resource Management Organization \\
TDEC & Tennessee Division of Environment and Conservation \\
UST & Underground Storage Tank \\
WSRC & Westinghouse Savannah River Corporation \\
& \\
& \\
&
\end{tabular}




\section{EXECUTIVE SUMMARY}

In 1991, the Energy Systems Groundwater Program Office was established for the purpose of "coordinating all activities associated with monitoring of groundwater on the Oak Ridge Reservation." In 1994, a groundwater program management plan, (ORNL/GWPO-001, 1994) approved by Senior managers of the three facilities on the Oak Ridge Reservation, and plant managers for the Paducah Gaseous Diffusion Plant and the Portsmouth Gaseous Diffusion Plant, was issued. That plan set the scope and objective for the Groundwater Program Office. Briefly, the mission was to ensure consistency and technical soundness of groundwater protection programs at all five facilities, serve as a focal point of contact for technical groundwater issues, and improve communications on groundwater concerns within Energy Systems and between Energy Systems and DOE, EPA, the sites, and the public (ORNL/GWPO-001, 1994). Funding for the Groundwater Program Office was shared between the Environmental Restoration Program and a combined five-plant overhead budget allocation.

The purpose of this report is to summarize the activities of the Groundwater Program Office in fiscal years 1995-1997 and document technical results achieved. One of the first contributions of the project was development and publication of a conceptual hydrologic framework for the Oak Ridge Reservation. This framework then served to guide research to fill important gaps in knowledge and suggest the most cost-effective approaches to site characterization and remediation. Examples of major goals include:

- Quantitative characterization of the role of matrix diffusion in slowing transport of contaminants and impacting the practicality of pump and treat options for aquifer restoration;

- The importance of geologic structure and preferred flow pathways in the near surface zone (including the role of stormflow);

- Evaluation of the importance of the deep groundwater system in contaminant migration; and

- Acquisition of three-dimensional groundwater flow and contaminant transport simulation capability for fractured porous media.

Major Lockheed Martin organizational changes began in 1995. The Environmental Restoration Program ended their direct funding support to the Groundwater Program Office and began involving the Groundwater Program Office staff as individual participants in site-specific projects. Simultaneously, the five facility organizations changed, new corporations were formed, and overhead budget allocations were reduced. In 1997, the central groundwater program was restructured. Research projects were ended, results were documented, and most emphasis was placed on providing limited 
senior-level hydrogeologic expertise to the five site Groundwater Protection Programs. It is anticipated that funding for the Groundwater Program Office functions will be reduced further beginning in fiscal year 1998. At that time, each facility will assume increased responsibility for its share of coordination and technical integration of groundwater activities.

The report that follows is structured to provide a general overview of the GWPO functions (Section 1), describe the hydrogeologic setting of the Oak Ridge Reservation (Section 2), summarize the research and development projects that have been conducted to provide a foundation for addressing site groundwater issues (Sections 3-7), summarize technical support accomplishments for the combined program by site (Section 8), and describe some examples of the useful products that have emerged (Section 9). 


\section{INTRODUCTION}

\subsection{PURPOSE}

This edition of the Lockheed Martin Energy Research Corporation (LMER) Groundwater Program Annual Report summarizes the work carried out by the LMER GWPO for fiscal years (FY) 1995-97. Previous reports have describe the GWPO's staffing, organization, and funding sources, so that information is not repeated here. By charter, the GWPO is responsible for coordination and oversight for all components of the groundwater program at the three Oak Ridge facilities [ORNL, the Oak Ridge Y-12 Plant, and the Oak Ridge East Tennessee Technology Park (ETTP, formerly K-25) Site], and the PGDP and PORTS, respectively. However, changes in available resources over the past two years mandate that the GWPO role be limited in scope.

While the basic objectives of the GWPO remain to assure a groundwater program that:

- complies with all applicable federal and state environmental laws, DOE orders, Executive Orders, and Energy Systems policies and procedures;

- is comprehensive and technically sound;

- ensures consistency of well installation, development, sampling, maintenance, plugging and abandonment, and data management and reporting throughout Energy Systems;

- ensures consistency in the technical approach that is used for all components of the groundwater program at all sites;

- provides a basis for trend analysis and predictive capability; and

- effectively communicates with DOE, EPA, the states, and the public,

the scope of involvement in recent years has focused on providing technical leadership to the site groundwater programs and to developing and publishing relevant technical information to guide groundwater management at the five facilities managed by DOE-OR. During FY97, the technical studies research and development tasks that were needed to fully develop the conceptual model for the ORR have been closed out. This report serves to document much of the efforts over the past three years and to signal a change in the role of the GWPO.

With the separation of LMER and LMES, impending change in the contracting mechanism from an $M \& O$ to an M\&I contract, the reindustrialization (privatization) of the East Tennessee Technology Park (ETTP) and the ongoing decrease in overhead support the role of the Groundwater Program Office needs to be revisited. While the groundwater needs across the five sites remain the same, the mechanism for providing meaningful technical oversight and coordination appears to require a stronger relationship with DOE as the number of prime contractors (and their subcontractors) proliferate, each with responsibility for smaller pieces of the action. In this environment it is necessary for DOE to oversee more groundwater related activities and to require some level of support to fulfill that role. 


\subsection{GWPO ADVISORY COMMITTEE REVIEWS AND COMMENTS}

During both FY95 and FY96, an advisory committee was invited to review GWPO program status and progress and offer recommendations for the coming year. The complete reports are included in Appendix A of this report. In summarizing the situation at the end of FY95, the committee stated that it considered the GWPO to be "...integral to the scientific understanding of groundwater systems, groundwater protection, and environmental remediation within the DOE sites managed by Lockheed Martin Energy Systems." They recognized the organizational changes that were in progress, and stressed that they considered it very important that the GWPO remain involved in evaluating potential off-site contaminant migration at all sites, preserve an "institutional memory" for technical groundwater knowledge, and continue to provide a coordinated technical oversight function.

In FY96, the committee noted the reduced funding support for the research component of the GWPO, and expressed concern at the loss of key scientific personnel. At FY96 levels, the research function was called "... hardly a critical mass for a comprehensive research program." The committee recommended consideration of retaining the research arm of GWPO, but was not in a position to suggest anything more specific than "... move into a more applied emphasis." They recommended that the GWPO increase efforts to "evangelize" and gain greater visibility. Their "... most significant recommendation" was that the GWPO staff increase communication at all levels.

In FY97, with the program continuing to shrink and the research portion of GWPO being phased out because of funding limitations, it was decided that an Advisory Committee review would not be held. Resources were instead dedicated to producing a three-year summary of program activities and attempting to document important data and findings for future use. With the decision by Lockheed Martin Energy Systems that they would not seek a contract renewal for Environmental Restoration work under the new management and integration structure, it seems that the need for the GWPO will increase if it is considered important to preserve institutional memory and technical coordination of the increasing number of subcontractors that is planned. Recent events involving tritium contamination of groundwater at Brookhaven National Laboratory have raised questions about the impact of new contracting practices on the Department of Energy's ability to provide adequate oversight of groundwater management. Some excerpts from the Integrated Safety Management Evaluation of the Brookhaven National Laboratory by the Office of Oversight Environmental, Safety and Health of the U.S. Department of Energy (http://tis-hq.eh.doe.gov/web/eh2/bnl/bnl_apr97.html\#Scope, April, 1997) illustrate: "Department of Energy Headquarters should also reconsider its direction, under contract reform, to reduce direct oversight of contractor environment, safety, and health performance and to rely primarily on performance metrics. While these metrics have value, particularly when tied to the operating contract, they do not serve as an effective mechanism to monitor the contractor's day-to-day environment, safety, and health performance. Effective Department of Energy line management oversight is even more essential in the absence of 
effective and sustained environment, safety, and health performance and a strong contractor self-assessment program. Coordinated and effective Department of Energy line management oversight is needed to implement the Department of Energy's ultimate responsibility for site operations, and to assure effective protection of the public, the workers, and the environment .... DOE effectiveness in monitoring BNL ES\&H performance has been very limited. This has included a failure to identify and resolve weaknesses in key ES\&H programs, such as groundwater monitoring and radiation protection, as well as essential management systems and processes, such as issues management, work planning and control, and ES\&H training and retraining. This weakness is at least partly attributable to DOE Headquarters direction, under the auspices of contract reform, to decrease direct DOE oversight of contractor operations and performance, and increase reliance on performance metrics." Since the Groundwater Program Office was established to provide independent oversight evaluations (self-assessment) and communicate them to the Department of Energy, these functions clearly are designed to strengthen DOE oversight. However, unless funding trends for the GWPO change, the organization will no longer be able to conduct its chartered roles and responsibilities, and thus will no longer serve a viable function.

\section{CONCEPTUAL HYDROLOGIC FRAMEWORK}

\subsection{HYDROLOGIC FRAMEWORK FOR THE OAK RIDGE RESERVATION: SUMMARY OF KEY ELEMENTS}

(D. D. Huff)

Geologic units of the ORR are assigned to two broad hydrologic groups: (1) the Knox aquifer - formed by the Knox Group and the Maynardville Limestone - in which flow is dominated by solution conduits and which stores and transmits relatively large volumes of water and (2) the ORR aquitards - made up of all other geologic units of the ORR - in which flow is controlled by fractures, and which may store fairly large volumes, but transmit only limited amounts of water (Hatcher, et al., 1992).

In profile, both the Knox aquifer and the ORR aquitards are divided into the following:

- The stormflow zone, a thin region at the surface in which transient, precipitationgenerated flow accounts for a significant fraction of the water moving through the subsurface. This zone is a major pathway for transporting contaminants from the subsurface to the surface.

- The vadose zone is an unsaturated zone above the water table.

- The water-table interval, a thin ( 1-3 m) permeable zone near the contact between regolith and weathered bedrock, where much of the flow associated with the continuously saturated zone occurs. Groundwater flow rates generally decrease rapidly with increasing depth beyond this zone (intermediate and deep groundwater intervals). 
- The intermediate and deep groundwater intervals are continuously saturated. $\sim 98 \%$ of groundwater flow occurs at depths $<30 \mathrm{~m}$.

- The aquiclude is a zone in which water movement, if it occurs, probably is on a geologic time scale.

Water in the aquitards travels along flow paths having lengths of tens to a few hundred meters before being discharged to local surface drainage ways. Water in the aquitards is at best a marginal resource. A typical well yields $<0.02 \mathrm{~L} / \mathrm{s}(0.25 \mathrm{gal} / \mathrm{min})$; in many places, wells are incapable of producing domestic quantities of water. Groundwater flow circulation rates decrease and solute residence times increase sharply with depth. Mean solute transport rate in the stormflow zone is on the order of meters per hour, but in the intermediate and deep intervals of the groundwater zone, representative transport rates are as low as a few centimeters per year. In the vertical, most groundwater flow in the aquitards occurs through a few widely spaced $(7-50 \mathrm{~m})$ permeable regions, which appear to be associated with individual dipping units that are highly fractured.

The Knox aquifer is the only true aquifer of the ORR and is the primary source of sustained natural flow in perennial streams, such as upper Whiteoak Creek, Walker Branch, Scarboro Creek, East For Poplar Creek, and Bear Creek. In some places the Knox aquifer can supply large quantities of water to wells. Flow volumes are significantly larger than in the aquitards, and flow paths are deeper. The potential groundwater flow path length in the Knox aquifer is substantially greater than in the aquitards - on the order of kilometers rather than tens of meters or a few hundred meters. The one strongly suspected instance of groundwater flow across the ORR boundary occurs along Chestnut Ridge, where water from the Knox aquifer travels $>2.5 \mathrm{~km}$ and discharges into Scarboro Creek.

There is no evidence of contaminant migration along deep, long subsurface flow paths. Virtually all mobile water in the aquitards is discharged to local streams within the ORR. However, it is likely that some flowpaths in the Knox aquifer lead to discharge points outside the ORR boundary.

Residence times of solutes near the water table in the aquitards range from a few days to a few years. In the intermediate and deep intervals, estimates of residence times derived from ${ }^{14} \mathrm{C}$ measurements and modeling are hundreds to tens of thousands of years.

Geochemical processes (adsorption and ion exchange) and the matrix diffusion process significantly alter chemical concentrations of solutes in the ORR groundwater. One result is retardation and storage of any contaminant in the rock matrix.

At the time the conceptual framework was published (Solomon, et. At, 1992.) The authors stated: "The conceptual framework is believed to be fundamentally complete and correct. The basic premises are unlikely to change with further findings. Some details remain uncertain, and additional data are necessary to prove and refine some parts of the 
framework." In reality, the framework is an evolving model that should continue to change as new information dictates.

\subsection{REVISIONS AND UPDATES TO THE CONCEPTUAL MODEL (G. R. Moline and D. D. Huff)}

Over the course of the past three years, there have been revisions and updates to the hydrologic framework as described by Solomon and others (1992), based upon research and new information. Some key additions are:

- The development of a perched water table within the root zone during storm events (stormflow zone) has been demonstrated in a study area that was denuded within the past 10 years for the installation of wells. Previous measurements were confined to an undisturbed forested watershed (Moore, 1988), leaving in question whether or not the observations were applicable to disturbed areas, such as the burial grounds on the ORR. New data indicate that while saturation occurs at $0.15 \mathrm{~m}$ below the surface during storms, no change in saturation is observed at or below $1.05 \mathrm{~m}$ below the surface for most storms. These observations demonstrate that a significant fraction of the recharge moves laterally within the stormflow zone, and that this effect can occur even in disturbed areas.

- The saprolite-bedrock transition interval is highly transmissive. Characteristics are similar to those described for the "transition zone" in other settings: less weathered than the overlying saprolite, more intensely fractured than the underlying bedrock (Dugan, 1996).

- The shallow groundwater zone is not very well mixed in spite of a high density of fractures in the saprolite and shallow bedrock. Water chemistry is highly spatially variable, and changes temporally with seasonal and storm-driven water level changes (Moline and Schreiber, 1992; Moline et al., 1998).

- Fracture-controlled flow is evident within the saprolite, transition zone, and shallow bedrock (Moline et al., 1998). Strike-preferential transport is evident, but may be more a function of strike-parallel fracture intersections rather than a dominance of beddingparallel fractures. Evidence from laboratory and field tracer tests suggests that the dominance of a given fracture set is dependent on the orientation of that fracture set relative to the local hydraulic gradient (Schreiber, 1995; Moline et al, 1998).

- Flow and transport anisotropy may be very different due to differences in the characteristics of the various fracture sets. Laboratory column work has demonstrated that, because of the dependence of matrix diffusion and sorption on the ratio of fracture porosity to fracture surface area, identical soil materials having very similar bulk 
hydraulic conductivities may produce very dissimilar tracer breakthrough curves that can be related to fracture characteristics (Moline et al., 1997).

- The tremendous contaminant storage capacity of the ORR shales and soil/saprolite has been demonstrated in numerous field tracer studies. The West Bear Creek Valley helium tracer test demonstrated that even with injections as short as 9 months; a huge secondary source was created that provided a nearly constant helium concentration within a fracture flow path for at least 19 months (Moline et al., 1998). This has important implications for the potential mass residing outside of waste disposal sites that have been leaking for decades.

- Field tests have demonstrated that the region of influence for pumping is large due to the low permeability of the matrix and low overall porosity of the fracture network, and is highly sensitive to the pumping rate. The affected region is not necessarily captured by the pumping well, however. Colloid tracer tests demonstrated that transport directions were altered by pumping below the transition zone, but the tracers remained within the transition zone. Thus, there is the potential to mobilize but not capture contaminants during pumping, and some question about the influence that pumping may have on secondary sources within the matrix.

- Gradient reversals can and do occur during storm events, driving transport in apparent "upgradient" directions. This phenomenon was observed during tracer testing at two West Bear Creek Valley field research sites (Moline and Schreiber, 1996; Moline et al., 1998). This has important implications for the siting of upgradient wells for background controls.

- Groundwater recharge values exhibit a range $(5-25 \mathrm{~cm} / \mathrm{y})$, depending on vegetative cover, soils, underlying geology, and topographic setting. A USGS study (Tucci, 1992) estimated recharge as ranging from $3-20 \mathrm{~cm} / \mathrm{y}$, based on groundwater modeling work in Melton Valley. More detailed recent modeling results (Clapp, 1997) indicate that runoff is distributed as $6 \%$ overland flow (source area runoff), $47 \%$ as subsurface stormflow, and $47 \%$ as "groundwater discharge." Hydrograph analysis showed storm runoff at Walker Branch Watershed was about $65 \%$ of total runoff. This result is consistent with the assumption that overland flow, most subsurface stormflow and a portion of groundwater discharge (probably from the water-table interval, as defined by Solomon, et al.) will all contribute to the storm runoff volume determined by hydrograph analysis methods. Given a typical annual runoff total of about $57 \mathrm{~cm}$, this would suggest that as much as $20 \mathrm{~cm} / \mathrm{y}$ are associated with more traditional concepts of flow in the perennial groundwater system. Earlier estimates were that only about $5 \mathrm{~cm} / \mathrm{y}$ of flow was associated with the stable groundwater flow system (Solomon, et al., 1992) 


\section{DATA CAPTURE AND DOCUMENTATION}

The Ground Water Program has completed projects to archive and document data sets that support the goal of providing quantitative data to demonstrate the role of matrix diffusion in fractured, porous media. Three such sets of data have been created: Results from a tritium tracer test that the US Geological Survey began in 1977; Results of a noble gas tracer test that was initiated in March, 1994 and continued into 1996; and Data from a sampling protocol experiment that used noble gas tracers.

\subsection{USGS TRITIUM TRACER TEST \\ (D. D. Huff)}

In 1977, D.A. Webster of the US Geological Survey initiated two tritium tracer tests to explore the relationship between weathering of regolith beds in shales of the Conasauga Group and groundwater flow through them. Data collection continued until 1982, but results had not been published. In October, 1992, a presentation at the Fifth Tennessee Water Resources Symposium (Solomon, et al., 1992) stimulated discussion about the matrix diffusion process and the potential relevance of Webster's data set. The outcome was a US Geological Survey Water-Resources Investigation Report (Webster, 1996) that described the experiment and presented the data in published form. Briefly, the results suggested that matrix diffusion could account for sustained (long term) concentrations of tritium in observation wells and the very slow movement of the centers of mass of the tracer plumes across the study sites. This also has implications for aquifer remediation. In addition to issuing the report, the data were provided to Ground Water Program staff at ORNL, and were archived and documented (Thompson and Huff, 1997). The data proved very useful to modeling studies on the importance of matrix diffusion, and represent results that are still of value today (Stafford, et al., in press). The data dictionary that was produced explains how the data are stored so they can be made available for future use.

\subsection{NOBLE GAS TRACER TEST DATA SETS (D. D. Huff)}

On March 11, 1994 at 1:00 pm EST, a noble gas tracer test was initiated in Bear Creek Valley by starting a continuous release of helium and neon gas into tubing submerged in well GW-484. The principles of the experiment are presented in Sanford et al., 1996 (WRR 32(6): 1635-1642). The experiment was designed to quantify the effects of matrix diffusion for weathered shales that are typical of waste sites on the Oak Ridge Reservation. Several open literature publications have been written to describe the work (e.g. Sanford and Solomon, 1995; Sanford and Moore, 1994; and Sanford et.al., 1996). Briefly, the results have established a quantitative basis for demonstrating the role of matrix diffusion in attenuating the rate of movement of contaminants in the typical geologic setting for waste sites on the Oak Ridge Reservation. They have also clearly demonstrated the importance of 
continuity of fractured zones in controlling the rate and direction of contaminant migration in the local geologic setting. However, in addition to published analyses of the results, the data gathered during the test have been archived in SAS data sets on the GWPO workstation. The data are organized by well number, and include results of helium and neon analyses, water level elevation, daily total precipitation, and remarks associated with individual tracer samples. The data reside in three primary SAS data sets: file trall.ssd01 contains 3,248 individual observations of relative helium and neon concentrations by well and individual sampling port; file levall.ssd 01 contains 42,206 individual observations comprising hydraulic head in key wells, temperature in the injection well, and precipitation amount; and file wellstr.ssd01 contains 63 individual observation records of well location and sampling port depth. Taken together, these data sets represent nearly two and one half years of detailed observations that are expected to serve as a basis for evaluating the importance of the physical diffusion process on transport of contaminants (e.g. volatile organic compounds) in this hydrogeologic setting.

\subsection{SAMPLING PROTOCOL TEST DATA SETS (G. R. Moline)}

There are two SAS data sets for the results from the sampling protocol tracing studies that have been archived (see Section 6.2) that have been archived: file trallhe.ssd01 contains helium concentration observations by date and well number (1,092 observations), and file wellstr.ssd01 contains the well location and physical description information for the observation wells used in the study.

Several other data sets have been developed in conjunction with the sampling protocol project. They include: Borehole flowmeter measurements, point dilution tests and core descriptions for GW821, GW822 and GW823. These data are published in Moline and Schreiber (ORNL/TM13029, 1996). Water chemistry data obtained in January and July, 1995 at 22 locations. These data are published in Moline et al. (1997), Schreiber (1996), and Schreiber et al. (1997); Water chemistry, CFC, and stable isotope data obtained at 83 locations on a quarterly, monthly, or storm-driven basis from October 1996 through January 1998. The sampling locations include two surface water locations, two precipitation locations, 12 stormflow wells, 19 vadose zone wells, and 48 groundwater wells. Sampling will continue through January 1998 . These data have not yet been published, but will provide the basis for a PhD dissertation that will be published as an ORNL document at project completion; Water level data for 79 locations, including hourly data for 15 locations and monthly data for 30 locations. Hourly precipitation data have also been collected since 1994, and these data will be included in the dissertation; Pumping test and colloid tracer test data obtained during 4 tests conducted in the summer of 1995. These data have not yet been published, but are contained in a peer-reviewed journal article that will be submitted for publication in March 1998; CFC data from 25 locations in Bear Creek Valley and 17 locations in Melton Valley, obtained during the summer of 1995 and again in the fall of 1996. Water chemistry data were obtained concurrently during the second sampling event. 
These data will provide the basis for a MS thesis examining the spatial variability of recharge that will be published as an ORNL document at project completion. All additional data are contained in Excel spreadsheet files, and plans are to incorporate these into SAS data sets on completion of the projects.

\section{GEOLOGY AND GROUNDWATER FLOW (G. R. Moline)}

The importance of geology on control of groundwater flow direction and rate has long been recognized for the Oak Ridge Reservation. Solomon et al. (1992) recognized two broad hydrologic groupings of geologic units: the Knox aquifer, formed by the Knox Group and Maynardville Limestone (where karst features may be an important control on groundwater movement), and the Oak Ridge Reservation Aquitards, which comprise the rest of the Reservation. Both hydrologic groupings exhibit fractures that are related to geologic structure and formation composition. Other important hydrologic considerations are associated with anthropogenic effects such as large cut and fill operations, and the presence of buried utilities, which may introduce external sources of recharge from leaking pipes, higher permeability pathways for water movement, and/or sumps that locally withdraw significant quantities of groundwater. Previous work has emphasized characterization of the hydrology of the aquitards, leaving gaps in understanding of the carbonate (Knox) flow systems and in the anthropogenic impacts associated with plant facilities. Over the past three years, emphasis has been placed on the carbonate flow system features and gaps in information for the aquitard system, as described in the following sections.

\subsection{PRELIMINARY KARST INVENTORY} (P. J. Lemiszki)

During the period 1995 through 1996, a project was conducted to create a comprehensive inventory of the karst features present on the US DOE Oak Ridge Reservation. A major objective was to lay the foundation for a full, area-wide framework for the karst system so subsequent interpretations would not be limited by potentially misleading smaller-scale results. Prior to this project, data were available from individual waste site studies, but were generally of too limited an areal extent to provide an overall picture of the system. The data from this recent project are intended to be used to develop groundwater testing and monitoring strategies, and for characterizing and conceptualizing the base and storm flow response of the karst system at a suitable scale for the entire Oak Ridge Reservation (Lemiszki et. al., 1997).

The project employed stereoscopic analyses of 1942 air photo stereo pairs, detailed field mapping of the entire Oak Ridge Reservation, reviews of old reports, topographic maps and drilling records, and interviews of knowledgeable researchers. The karst features that were included are sinkholes, caves, sinking streams and springs. Results were compiled digitally 
in spreadsheets that are linked to maps, as well as location maps for all significant features. A total of 555 sinkholes were mapped across all carbonate units. Of that total, $86(16 \%)$ appeared to be active, based on physical characteristics. The field mapping results database appears to best reflect the karst features present today on the Oak Ridge Reservation. The results are contained in GIS data sets that reside on the GWPO workstation (gwater). A total of 49 caves were also identified and mapped. Mapping in these caves has provided insights into the stratigraphic and structural controls on cave passages that act to transport soil and water from active karst features.

An example of the interpretive use of these data for conceptual understanding of contaminant transport in karst systems to support environmental restoration projects is contained a report prepared by P.J. Lemiszki as a complementary study to work sponsored by the GWPO. Through study of exposed, connected open fractures and bedding planes at the K-25 site, a preliminary conceptual model was developed as an explanation of what may be occurring with subsurface flow in the vadose zone. Figure 1, taken from the K-25 report (K/ER-259, 1995, Figure 39) illustrates the possible role of geologic factors that govern flow of groundwater in dipping carbonate rocks, typical of conditions on the Oak Ridge Reservation. The complexity of the flow system shown makes it easy to see why attempting to understand contaminant transport based on observations from wells alone, without geologic structural analysis, is inadequate.

\subsection{POROSITY OF MUDROCKS (J. Dorsch and R. B. Dreier)}

In the 1994 GWPO annual report, one of the modeling studies highlighted the importance of matrix porosity for understanding and quantifying the role of matrix diffusion and secondary sources in remedial action assessment. This recognition was accompanied by the realization that porosity data for the aquitard units on the Oak Ridge Reservation was virtually non-existent. That observation resulted in a project to evaluate the porosity of the saprolite matrix on the Oak Ridge Reservation. Mudrock-saprolite specimens from Bear Creek Valley, derived from the Nolichucky Shale through weathering, were analyzed with helium and mercury porosimetry. Average effective porosities (determined by helium porosimetry, which was judged to provide the best estimate for true (maximum) effective porosity) were found to be $16.1 \%$ for mudrock fragments and $39.0 \%$ for groundmass. Mudrock refers to all types of fine-grained siliciclastic rock; however, material sampled in this study was predominantly mudstone and claystone. No siltstone, silt-shale, or marlstone specimens were analyzed. Groundmass consists of heavily weathered mudrock material which still has coherence and shows original sedimentary and tectonic structures. The progressive effect of weathering is apparent as increased effective porosity and decreased bulk density. Pore-throat size distribution curves for mudrock saprolite fragments (skewed 
ORNL $97-126666 / \mathrm{Imh}$

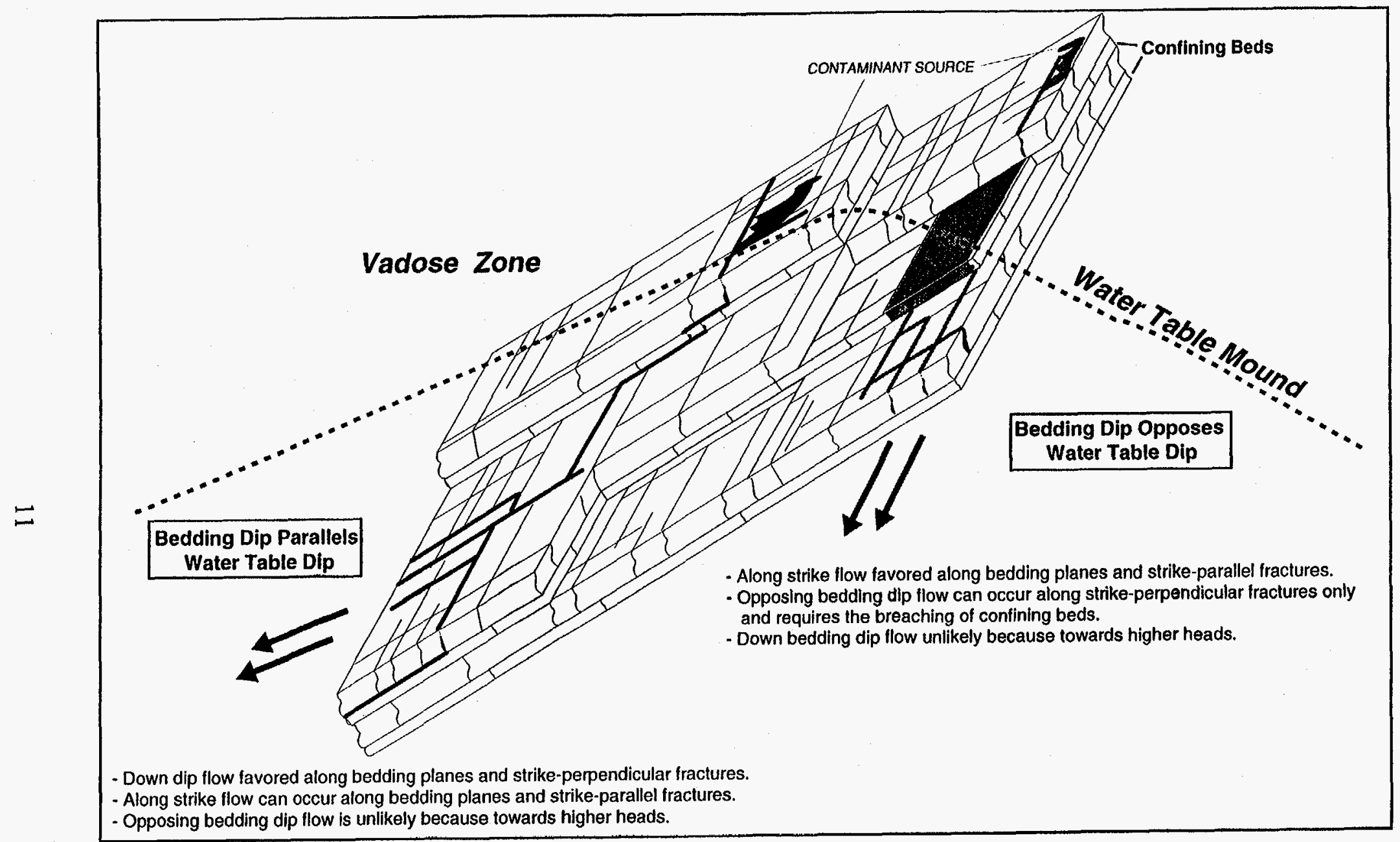

Figure 1. Schematic of some various geologic factors that influence flow below the water table in dipping carbonates that is based on the relationship between the inclination of the water table and the dip direction of bedding. Assumes that only the orthogonal extension fracture sets are present. K/ER-259, July 1995 
right, modes 5 to $20 \mathrm{~nm}$ ) were distinctly different from corresponding curves for saprolite groundmass (skewed left, modes 1200 to $5000 \mathrm{~nm}$ ). Calculated interval effective porosities, which characterize combined mudrock-fragment and groundmass effective porosities, range from $51.3 \%$ near the surface to $26.2 \%$ at greater depth, mirroring the weathering profile. The results are shown in Figure 2, taken from ORNL/GWPO-025 (Dorsch and Katsube, May 1996, Figure 11). The calculated interval effective porosities are probably best suited for the task of modeling and evaluating matrix diffusion as a transport mechanism within the saprolite mantle. These results are particularly relevant for future modeling studies to evaluate the persistence of secondary contaminants such as VOCs in the near-surface zone and the likely effectiveness of alternative remedial options for either removing or controlling releases.

\section{Effective Porosity vs Depth}

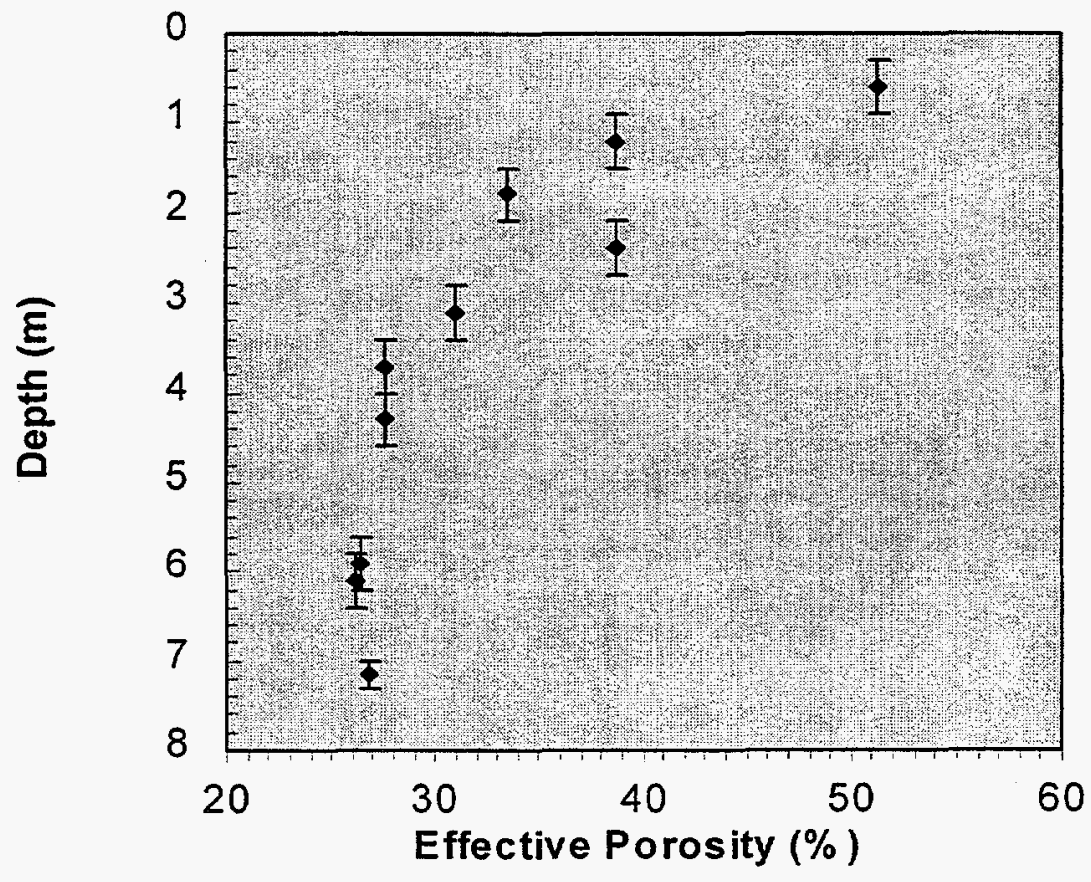

Fig 2. Calculated interval effective porosity as a function of depth. Porosities are based on helium porosimitry. Adapted from Dorsch and Katsube, ORNL/GWPO-025, May 1996. 


\section{MODELING FLOW IN FRACTURED ROCK SYSTEMS}

\subsection{WATER BALANCE MODELING (R. B. Clapp)}

There were two main objectives for the water-balance modeling project: The first was to determine whether or not it was possible to reliably estimate the surface water hydrograph for Bear Creek using an area-weighted composite of runoff from the two dominant geologic units on the Oak Ridge Reservation (the Knox Aquifer and the ORR Aquitard). Observed hydrographs from the West Branch of Walker Branch Watershed, representing the Knox Aquifer and Center Seven Creek, representing ORR Aquitards were combined, using the proportion of the basin area each geologic unit contributed to the flow at the Bear Creek monitoring station. The West Fork is known to gain flow due to groundwater input from sources outside the watershed (probably from the adjacent East Fork watershed). The measured flow at Walker Branch Watershed was adjusted by subtracting the groundwater inflow, computed from estimates reported in earlier studies. Subsequently, it was determined, based upon relative fraction of the total basin area represented by the two major geologic units, that the volumetric daily total observed at Bear Creek could be reliably estimated by combining $44 \%$ of the adjusted Walker Branch Watershed flow and $56 \%$ of the Center Seven Creek flow. To obtain reliable hourly hydrographs, it was necessary to route flows from various parts of the basin, using standard techniques. This result was important because it showed that reference watershed runoff could be used, weighted by fraction of the basin represented by each reference area, to estimate flows in ungaged basins using an objective measure of area-weighted contributions from the two dominant geologic runoff units on the Oak Ridge Reservation.

The second objective of the water balance modeling project was development of an improved version of a runoff model (TopModel Plus) that is primarily related to basin topography and geometry, and uses climatic variables as the forcing functions for runoff generation. An operational version of TopModel was updated to include separate functions for a stormflow zone, the saturated groundwater flow zone, and an explicit linkage that allows drainage from the stormflow zone to the saturated zone based on soil drainage properties. In addition, the model was updated to allow both stormflow and groundwater flow to cause surface saturation adjacent to the stream (the variable source area). Application of this model to Center Seven Creek suggested that overland flow, subsurface stormflow and groundwater discharge yielded $6.2,46.6$ and $47.2 \%$ of the total annual runoff respectively. This implies that average annual recharge to the groundwater zone in the ORR Aquitards was $23 \mathrm{~cm}$ (Clapp, 1997), although as noted earlier, less than $20 \mathrm{~cm} / \mathrm{y}$ represent water associated with the perennial saturated zone. This value does not match earlier estimates presented in the Hydrologic Framework, which were on the order of only $5 \mathrm{~cm}$ (Solomon et al., 1992). These seemingly conflicting estimates underscore the difficulty associated with quantifying contributions from different portions of the subsurface flow system. An earlier modeling study by Tucci (1992) reported that in Melton Valley, which is underlain mostly by ORR 
Aquitard units, average annual recharge rates were estimated to range from about 3 to $20 \mathrm{~cm}$. Center Seven Creek is located in the upper part of Melton Valley, thus the estimated recharge rates ought to be comparable. On balance, however, these results suggest that the hydrologic framework (conceptual model) for the Aquitards should be revised to indicate annual groundwater recharge rates that probably range between 5 and $25 \mathrm{~cm}$, and are more likely to average near $20 \mathrm{~cm}$ over a large watershed area underlain by ORR Aquitard geologic units.

TopModel Plus does not simulate the spatial pattern of groundwater flow, therefore it does not estimate the depth of the active aquifer system. Cross-sectional and areal ground-waterflow model results reported by Tucci (1992) indicated that from 91 to $96 \%$ of the recharge to the water table flows within the upper 50 feet of the groundwater system, and $97 \%$ of the recharge flows within the upper 100 feet.

\subsection{FRACTURE FLOW VERSUS EQUIVALENT POROUS MEDIA MODELS (G. R. Moline, L. E. Toran, L. D. McKay and P. L. Stafford)}

A new version of the University of Waterloo's 3-dimensional fracture flow and matrix diffusion model (FRAC3D) has been tested on the Oak Ridge Reservation. This model is particularly suited to the hydrologic setting of the ORR because it accounts for flow and transport in both fractures and the porous media surrounding the fractures, in addition to explicit quantification of matrix diffusion effects on solute migration. Modification of the model was made for the ORR, including addition of the capability to incorporate tilted fractures on tetrahedral elements and enhanced post-processing capabilities using the Groundwater Modeling System (GMS) software.

GWPO funded two modeling projects using FRAC3D: a long term tritium tracer test in Melton Valley and a helium tracer test in Bear Creek Valley. In addition, the Waterloo codes have been used elsewhere on the ORR to evaluate along strike flow of radionuclides in Bethel Valley from the area near corehole 8 to Fifth Creek (R.H. Ketelle, personal communication) and to model column tracer experiments from intact columns ( $\mathrm{O}^{\prime}$ Brien et al., in preparation). The results of the first two projects are briefly described here.

\subsubsection{Tritium Tracer Test Modeling (P. L. Stafford, L. D. McKay, and L. E. Toran)}

Tritium was injected into the saprolite zone north of Burial Ground 4 (BG4) in July 1977 by researchers from the USGS (Webster, 1996). Tritium concentrations were monitored in an array of wells surrounding the injection well for approximately 5 years, then once again in 1993 (16 years after the injection). The resulting plume was characterized by rapid migration of the leading edge of the plume (up to $0.4 \mathrm{~m} /$ day), slower movement of the center of mass (on the order of $0.009 \mathrm{~m} /$ day) and a very slow decline of concentration in the "tail" of the 
breakthrough curve. In addition, the plume exhibited an large transverse spreading, with the width of the plume approximately equal to its length (Fig. 3).

Both equivalent porous media and fracture flow modeling were used to evaluate the tritium tracer experiment results. Equivalent porous media models incorporate the influence of fractures into the model parameters. These models are easier to apply, because fewer parameters are used in the model and they tend to be less computationally intense; however, the validity of the approach is still in question. The equivalent porous media model was used to (1) evaluate plume behavior (such as the broad shape of the plume), (2) investigate relative sensitivity of plume development to model parameters, and (3) compare measured and model-predicted concentrations 16 years after the start of the experiment (see Fig. 4). The study showed that equivalent porous media models can be successfully applied to a complex, highly fractured system, provided that there is sufficient monitoring data (5 years of observations in this case) available for calibration of the model (McKay et al., in press). In addition, a model with fractures imbedded in a porous medium (FRAC3D) was used to examine how fracture geometry can influence dispersion in the broad tritium plume observed near BG4 (Stafford et al., in press). The model results showed that a few large aperture fractures can greatly affect plume behavior, depending on their orientation and connectivity. Such fractures could be very difficult to detect by hydraulic testing. Instead, the plume geometry could be used to indicate behavior caused by major fractures.

\subsubsection{Modeling the Bear Creek Valley Helium Tracer Test (L. E. Toran and G. R. Moline)}

A helium tracer injection was conducted from March 1994 to December 1994 (with monitoring of breakthrough continued through July 1996) on a site in Bear Creek Valley on the ORR that was instrumented with a mulitport monitoring wells. The helium moved predominantly along-strike, perpendicular to the hydraulic gradient, except during storm events. This tracer test emphasizes the point that both the hydraulic gradient (driving force) and local permeability, which may be associated with fractures, must be considered together to obtain the best indicator of transport pathways (Moline and Schreiber, 1996).

Although fractures are only hypothesized to be the cause of the along-strike tracer movement, modeling can be used to help confirm that the correct processes and parameters are included in the conceptual model. FRAC3D was used to construct a model with a dominant fracture set tilted with respect to the hydraulic gradient. Using a set of parallel tilted fractures, slightly offset from the perpendicular of the hydraulic gradient, the observed concentration patterns could be reproduced. That is, high concentrations were modeled perpendicular to the gradient and low concentrations along gradient. Although the exact concentrations were not matched, reproducing the general pattern lends support to the conceptual model and an understanding of important factors. 

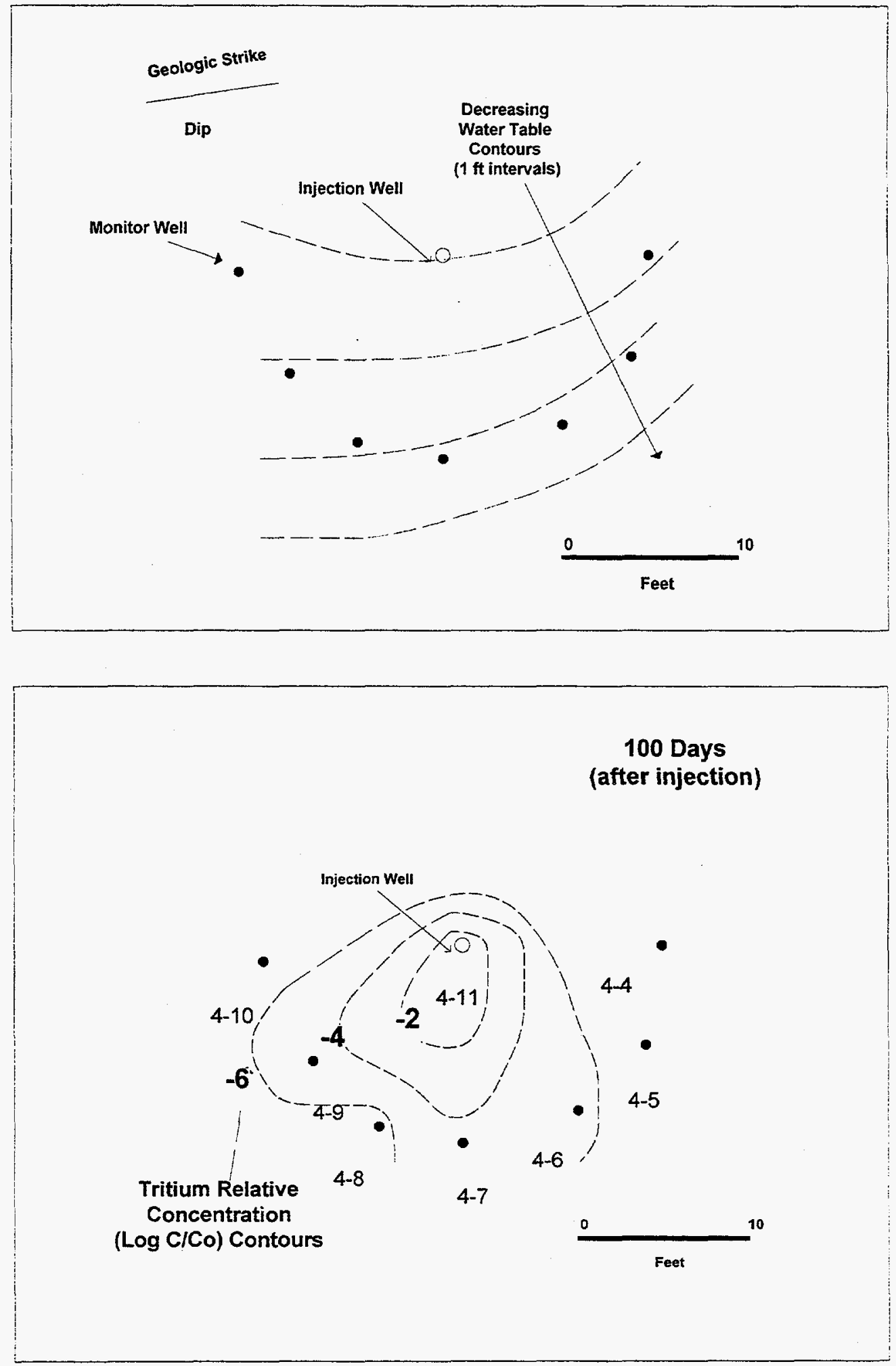

Fig 3. USGS tritium tracer experiment site and distribution of wells and tritium plume. 


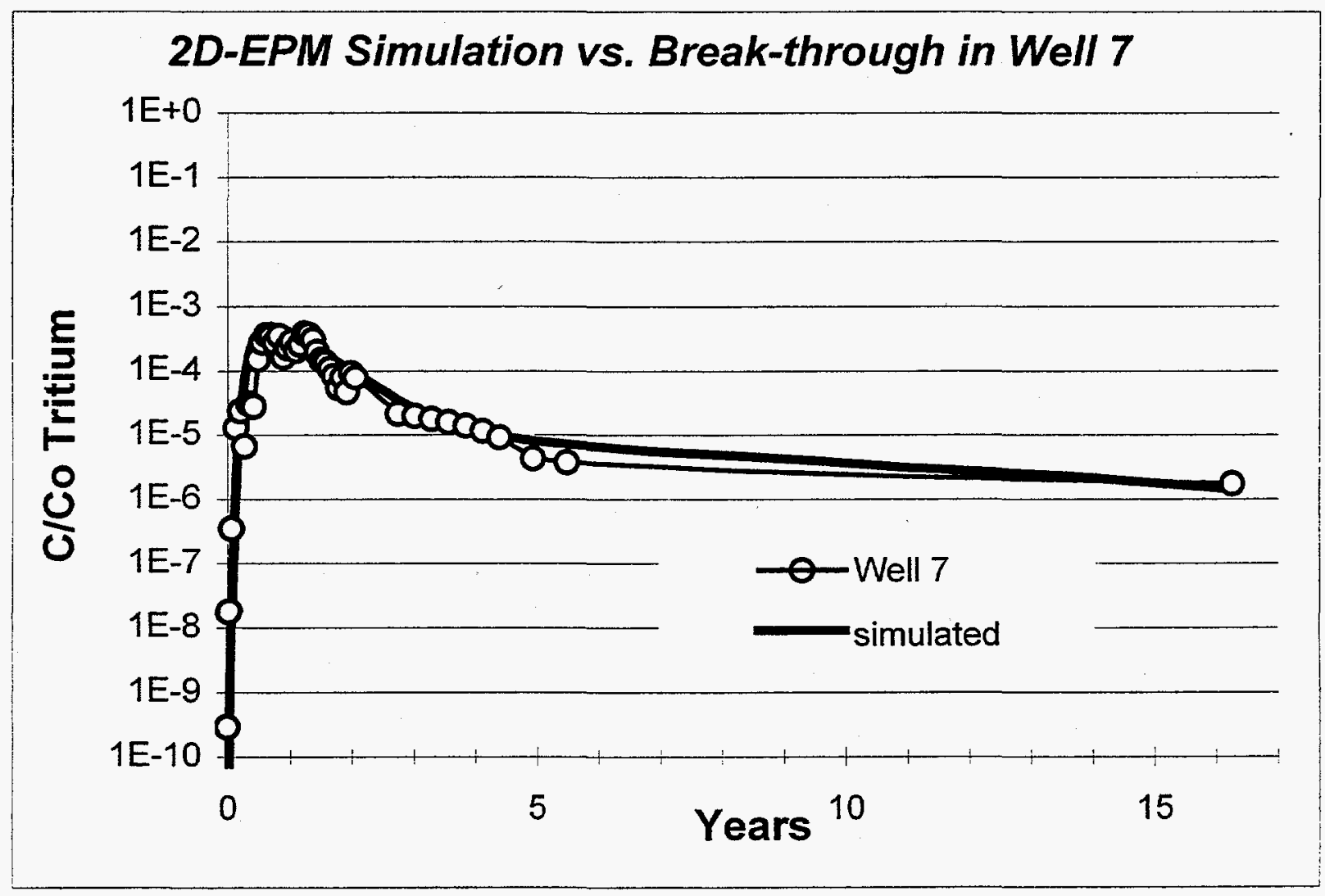

Fig 4. Tritium breakthrough with time: modeled and measured. Note that simulated curve magnitude was adjusted to overly observations in the first 5 years. (Figure courtesy of Paige Stafford). 


\subsection{VARIABLE DENSITY AND MULTIPHASE MODELING (L. E. Toran and Intera, Inc.)}

This task involved both evaluation of multiphase models and application of a specific variable density model to a plume on the ORR. Some of the work was subcontracted to Intera, Inc. of Austin, TX. Several multiphase transport problems exist at K25, Y12, and Portsmouth. The goal of this work was to become more familiar with modeling techniques applicable to these problems and eventually develop expertise that could be used to address the problems. Multiphase modeling is used for contaminants that occur as a separate phase from groundwater (such as non-aqueous phase liquids). Variable density modeling is used for contaminant plumes that have a different density than fresh water, and are thus influenced differently by gravitational forces. The non-aqueous phase liquids often have a different density than water; however, not all variable-density contaminant plumes (e.g. highly saline plumes) exist in both dissolved and non-aqueous phases in groundwater.

\subsubsection{Multiphase code evaluation (Intera, Inc.)}

Intera, Inc. evaluated several potentially useful multiphase codes for predicting fate and transport of non-aqueous phase liquids (NAPLs) at Oak Ridge sites. Reeves (1996) briefly described the following codes: MAGNAS, MOFAT, SWANFLOW, T2VOC, and UTCHEM. More details are provided for T2VOC, which is a 3-dimensional multiphase model derived from the TOUGH family of codes. Because of its thermal capability, T2VOC can be used to simulate NAPL removal via steam injection, a unique feature. T2VOC also has the ability to simulate dual permeability and dual porosity media, which is particularly relevant for Oak Ridge sites.

\subsubsection{Variable density model of the $\mathbf{S} 3$ Ponds nitrate plume (L. E. Toran and Intera, Inc.)}

A series of simulations using a two-dimensional $\mathrm{x}-\mathrm{z}$ model (SWIFT) with the $\mathrm{x}$-direction tilted at 45 degrees were conducted to determine a mechanism which could explain the high nitrate concentration and high head observed approximately $400 \mathrm{ft}$ below ground surface near the S-3 ponds at Y-12 (multiport groundwater monitoring system in well GW134). It was hypothesized that density driven flow of high nitrate water occurred downward from the S3 ponds and forced contaminants to this depth despite a natural gradient in the opposite direction. Several scenarios were tested (Jones et al., 1996).

The first scenario used a homogeneous dipping formation that had a within-bedding vertical to horizontal anisotropy ratio of $10: 1$ in hydraulic conductivity $\left(\mathrm{K}_{\mathrm{x}}: \mathrm{K}_{\mathrm{z}}=10: 1\right)$. This model predicted no nitrate concentration or head increase at the $400 \mathrm{ft}$. depth in monitoring well GW134. The second scenario used the same assumption for the anisotropy ratio, but included a 20 foot thick, high permeability zone extending along the dip of the formation from the S3 ponds to within $65 \mathrm{ft}$ of GW134. This scenario yielded high nitrate 
concentration and a head increase at depth. The magnitude of the nitrate concentration and head were dependent on the value of the hydraulic conductivity assigned to the high permeability zone. The simulations suggested that a combination of anisotropy and heterogeneity is needed to explain the high nitrate and head values in GW134, and that density driven flow is a plausible cause of the observed contaminant spreading.

\subsubsection{Summary}

Although equivalent porous media models will dominantly be used in regional, whole-valley models of the ORR (e.g., West and Toran, 1994), studies on the scale of waste sites will clearly benefit from the availability of parameters and models tested here using dual permeability models. The model calibrations described here are site-specific, but nonetheless results such as those from the tritium tracer study analysis indicate that long times may be required to flush contaminants from fractured porous media. Tools for a better understanding of plume behavior and remediation options are now available through these models.

\section{FIELD EVALUATIONS}

\subsection{WEST BEAR CREEK VALLEY NOBLE GAS TRACER TEST (D. D. Huff and W. E. Sanford)}

The West Bear Creek Valley Noble Gas Tracer Test was designed to study the effects of matrix diffusion on the transport of dissolved helium and neon in the shallow groundwater system. It also produced techniques for use of inert gas tracers for evaluating flow in the fractured and weathered rock matrix (e.g. Sanford et al., 1994; Sanford and Solomon, 1995; and Solomon, et al., 1997). Development of a gas injection method and diffusion sampler design was an important product of this work (Sanford, et al., 1996). By using tracers with identical properties except for molecular diffusion coefficients, differences between tracer behavior demonstrated that physical diffusion is an important control on solute transport in Oak Ridge Reservation aquitards. Other information that was derived from test results included apparent values for fracture spacing, fracture aperture and matrix porosity. These results established the basis for groundwater transport modeling that includes the diffusion process and is therefore more reliable than previous work to assess remediation options.

The noble gas tracer test began on March 11, 1994. Initial observations of both helium and neon breakthrough indicated migration velocities of greater than $3 \mathrm{~m} / \mathrm{d}$ in the fractures, even though there were no disturbances to the hydraulic system resulting from the test. As anticipated, neon was enriched with respect to helium, because it has a lower tendency to diffuse into the matrix. Tests with bacteria and non-diffusing tracers indicated migration velocities in fractures exceeded $40 \mathrm{~m} / \mathrm{d}$ under storm flow conditions. On March 29, 1995 ( $1530 \mathrm{hrs})$, the gas tracer input was discontinued, but measurements of tracer concentration 
in observation wells were maintained until August, 1996. Subsequent samples showed relative enrichment of helium with respect to neon, as predicted, because diffusion out of the matrix was now controlling observed concentrations. Overall, the tracer test demonstrated the important role of physical diffusion in controlling transport of solutes with large diffusion coefficients and provided the data base to derive modeling parameters for fate and transport of dissolved contaminants such as trichloroethylene.

Techniques initiated at the West Bear Creek Valley test site have been applied to other sites. At Waste Area Grouping 4, a site at the Oak Ridge National Laboratory that was used in the 1950 's for disposal of radioactive wastes, it was desirable to show a direct link between ${ }^{90} \mathrm{Sr}$ sources that had been located by site investigation and the seeps where releases occurred. To accomplish this goal, noble gas tracer injections were conducted in small-diameter wells at or near the primary ${ }^{90} \mathrm{Sr}$ sources. Passive samplers were used at down gradient locations, where sampling wells already existed, to attempt to determine flow pathways and approximate travel times for groundwater in, and downslope from, trenches. Some success was achieved in spite of very dry conditions and the short time interval available for conducting the work. At each area of interest, multiple gas tracers were injected for about three months. In the area of the strongest ${ }^{90} \mathrm{Sr}$ releases, both neon and helium were detected in a well roughly 140 feet away after two months. The implication was that elevated ${ }^{90} \mathrm{Sr}$ values near the well where tracers were detected probably resulted from sources in the vicinity of the tracer injection sites. At a second study area, helium was detected in a downslope well after about 70 days, at a distance of about 40 feet. These confirming tests strengthened the case for concluding that the correct targets for source-control actions had been identified.

\subsection{SAMPLING PROTOCOLS FOR FRACTURED MEDIA}

(G. R. Moline, S. J. Van der Hoven (University of Utah), M. E. Schreiber (University of Wisconsin - Madison) and B. E. Dugan (University of Minnesota)).

\subsubsection{Scope and Objectives}

The complexity of the flow system at the ORR raises concerns about the representativeness of samples obtained utilizing currently prescribed purge procedures and existing monitoring well construction specifications. According to the site conceptual hydrologic model, the majority of groundwater flux within the saturated zone moves through a network of fractures that comprise only a minute percentage of the pore volume in the ORR aquitards. These fractures provide pathways for rapid transport of contaminants. Purging large volumes from low yield formations results in a large radius of influence and as a result, samples may be representative of fracture fluids outside of the local region surrounding the well, potentially causing contaminants to move through the system at accelerated rates and along disrupted flow paths. In addition, monitoring wells are constructed such that they use large screened intervals that may or may not intersect active flow zones. Thus, standard construction can 
mask the vertical distribution of contaminants and prevent discrimination of contributions from matrix and fracture zones.

The objectives of this project were to evaluate the representativeness of standard sampling methods for fractured porous media such as that underlying the Oak Ridge Reservation through extensive field testing at a field research site in West Bear Creek Valley. The aspects of sampling methods tested were purge volume, well construction, and location in space and time.

\subsubsection{Approach}

Sampling methods were evaluated by (1) assessing the spatial and temporal variability of groundwater composition and transport characteristics, (2) comparing standard screened-well vs. multilevel-well construction, and (3) measuring the region influenced by standard purge techniques.

The field site had previously been instrumented with 7 screened wells: a fully-screened injection/pumping well and 3 well pairs situated updip, downdip, and along strike of the fully-screened well (Gierke et al., 1988). The pumping well is screened from $6-22 \mathrm{~m}$ bgs and the shallow and deep wells are screened from 4-7 $\mathrm{m}$ bgs and from 19-22 $\mathrm{m}$ bgs, respectively. Three additional boreholes were drilled and continuously cored, and borehole characterization was done using flowmeter and point dilution testing (Moore and Young, 1992; Sanford and Moore, 1994; Moline and Schreiber, 1996). The boreholes were subsequently instrumented with multilevel samplers to facilitate discrete fracture zone monitoring and comparison with standard screened wells. Screened intervals are, with a few exceptions, one foot thick and are located along demonstrated flow pathways between 4 and $22 \mathrm{~m}$ bgs.

Variability in flow and transport properties was assessed through a series of four applied tracer tests and through extensive sampling for water chemistry and environmental tracers. An initial ambient flow helium tracer test was conducted over a 2-year period (Moline and Schreiber, 1996; Moline et al., 1998). A passive injection and sampling method was used (Sanford et al., 1996), and samples were obtained 2-3 times per week from the 7 screened wells. A second ambient tracer test was initiated using $\mathrm{SF}_{6}$, but was terminated after 3 months of injection due to the presence of high background concentrations that complicated interpretation of the test. Two radially-convergent colloid tracer tests were conducted to evaluate fracture connectivity and region of influence during pumping (Moline et al., 1995; Moline et al., in prep.). The first was a short scale (3-m) test using PRD-1 and MS-2 bacteriophage and two types of 0.5 micron fluorescent latex microspheres injected into three separate multilevel ports and a shallow screened well. Samples were obtained while pumping from a nearby screened well at a rate of $1 \mathrm{~L} / \mathrm{min}$ for three well volumes (three times the volume of standing water in the well casing). A second large scale $(20-\mathrm{m})$ test consisted of injecting ice-nucleating (INA) bacteria and 10 differently labeled DNA-tagged silica 
microspheres into 10 injection ports and conducting a series of 3 pumping tests using deep (22-m) and shallow (4-m) pumping wells. Each pumping test consisted of 24 hours of pumping followed by 24 hours of recovery. Samples were obtained from the pumping well for all of the tracers, and water levels were monitored at 24 locations.

Water chemistry was initially sampled from discrete zones in 3 boreholes using a specially designed fracture sampler. Subsequently, samples were obtained from 7 screened wells and 15 multilevel well ports during two sampling events, once during the winter high water conditions and once during the summer low conditions (Schreiber, 1995; Schreiber et al., in review, Moline et al., in press). Samples were analyzed for alkalinity, major and minor ions, and total organic carbon (TOC). Beginning in November 1996, an intensive sampling and monitoring project was initiated to capture seasonal and storm-related variations in water chemistry across a 100-acre portion of West Bear Creek Valley (Van der Hoven et al., 1997). The project includes monthly sampling and water level monitoring over the entire study area, continuous water level monitoring at two intensively-instrumented sites within the study area, and winter and summer storm sampling events at the latter two sites. Sampling sites include the stormflow, vadose, shallow groundwater, and intermediate groundwater zones as well as precipitation and surface water. Analytes include alkalinity, major and minor ions, ${ }^{18} \mathrm{O} /{ }^{16} \mathrm{O}$ ratio, deuterium/hydrogen ratio, $\mathrm{CFCs}$ and field parameters. This project will continue through January 1998.

\subsubsection{Discussion}

The initial helium tracer test demonstrated preferential flow and transport along strike, perpendicular to the average hydraulic gradient which is roughly parallel to dip. Consistent breakthrough occurred in both along-strike wells 51 days after the start of injection, corresponding to a groundwater velocity of $0.28 \mathrm{~m} / \mathrm{d}$ at the front of the tracer plume. However, helium was observed in downdip and along-strike wells during the first round of measurements nine days after the start of injection. This corresponds to a minimum groundwater velocity of 0.68 and $1.7 \mathrm{~m} /$ day, respectively. No consistent breakthrough occurred in the downdip wells, although helium transport to both updip and downdip wells was evident in conjunction with storm events. Subsequent.continuous monitoring confirmed the occurrence of gradient reversals during storm events that would account for the presence of helium tracer in wells that under baseflow conditions would be upgradient of the injection well.

Background sampling prior to initiation of $\mathrm{SF}_{6}$ injection demonstrated high background levels of $\mathrm{SF}_{6}$ in many of the multilevel ports during a period of rapid water level decline associated with spring foliage growth and a two-week period without rain. $\mathrm{SF}_{6}$ levels dropped to atmospheric levels when the rains began again and the water level decline slowed. This high background was attributed to greater contributions of older water from either matrix or deep groundwater sources associated with higher historical atmospheric releases

of $\mathrm{SF}_{6}$ during uranium enrichment. Because $\mathrm{SE}_{5}$ concentrations in the observation wells 
never rose above the highest background levels observed, $\mathrm{SF}_{6}$ injection was terminated after 3 months.

A high degree of borehole mixing was evident from comparison of the water chemistry obtained from the discrete fracture samples taken from the boreholes, multilevel well samples, and screened well samples. Only minor variability was seen in the discrete fracture samples, and the chemistry was essentially identical to that obtained from the fully-screened well. However, large variability was observed in the water chemistry samples obtained after multilevel wells were installed in the same boreholes where the fracture samples were obtained. The lack of chemical variability in the fracture samples could be attributed to borehole mixing and either penetration of borehole fluids into the adjacent formation or chemical exchange between formation and borehole fluids. A zone of high $\mathrm{Na} / \mathrm{Ca}$ ratio and high $\mathrm{SO}_{4}$ was observed in each of the three multilevel wells but at different depths. When mapped in 3D space, these zones described a planar feature oriented perpendicular to bedding and roughly parallel to the average hydraulic gradient. This feature is both overlain and underlain by groundwater having a low $\mathrm{Na} / \mathrm{Ca}$ signature. These observations are consistent with deep groundwater discharge along bedding-perpendicular fractures that has undergone some dilution, accounting for the low TDS compared to that expected for older groundwater, but that is constrained within a discrete flow pathway that prevents full mixing with the surrounding groundwater. The overall $\mathrm{Ca}-\mathrm{HCO}_{3}$ chemical signature in the fully screened well indicates that the deep $\left(\mathrm{Na}-\mathrm{Ca}-\mathrm{HCO}_{3}\right)$ groundwater flux is small relative to the shallow $\left(\mathrm{Ca}-\mathrm{HCO}_{3}\right)$ groundwater flux. Ongoing water chemistry sampling and analysis is providing a more complete picture of the spatial and temporal variability, and is pointing to changes in the mixing ratios of younger and older waters driven by seasonal variations and storm events (Van der Hoven et al., 1997).

The colloid tracer tests and pumping tests provided information on fracture connectivity and region of influence during pumping. The discrete nature of transport pathways in the saprolite and shallow bedrock was confirmed by the colloid transport patterns. In the smallscale test, colloids were transported to the deep $(20-\mathrm{m})$ pumping well from the deep multilevel port only. The shallow ports and the shallow well immediately above the pumping well were not affected by the pumping. While the intermediate port was drawn down by the pumping, no colloids were transported to the pumping well. In the larger scale tests, rapid drawdown was observed in the deeper ports along strike and the shallow ports updip of the deep pumping well. However, the colloids injected into those ports were not transported to the pumping well during either of two 48-hr pumping tests. Surprisingly, when a shallow pumping test was initiated, the updip colloids were present in large concentrations in the first sample obtained. Intermittent transport of nearly all of the colloids to the shallow pumping well occurred during the final test. The shallow pumping well is screened over the zone of transition between the highly weathered saprolite and the more competent bedrock. Preferential transport through this zone is consistent with other observations that indicate a higher transmissivity through this zone than either the overlying or underlying materials (Dugan, 1996). 
The immediate drawdown of water levels as far as $20 \mathrm{~m}$ away from the pumping well demonstrated the large radius of influence for pumping in low-permeability fractured rocks. CFC sampling during the initial phase of the first deep well pumping test indicated that the water was getting older as drawdown developed. This is consistent with observations from $\mathrm{SF}_{6}$ background sampling.

\subsubsection{Conclusions}

Flow and transport characteristics in the fractured porous rocks underlying the Oak Ridge Reservation are highly variable in both time and space. Large seasonal and storm-related changes in water levels results in changes in water composition and transport directions. All of the study results are consistent with a poorly-mixed shallow groundwater system. Samples obtained from wells that are screened over multiple flow paths represent fluxweighted averages from potentially widely-spaced sources. Because of the low matrix permeability and low fracture porosity, fracture fluids are drained rapidly during pumping, and large purge volumes even at relatively low pumping rates $(0.3 \mathrm{~L} / \mathrm{min})$ result in potential capture of groundwater on the order of tens of meters away from the sampling location and with increasing contributions from older groundwater sources. Drawdown is highly sensitive to the pumping rate, and the removal large purge volumes without significant impact on the surrounding areas would require very low pumping rates over unreasonably long times. On the other hand, a minimal amount of purging is required to ensure that borehole effects are minimized. Low-flow pumping combined with isolation of the sampling interval and monitoring of water quality will minimize the deleterious effects of purging and ensure local representativeness. Water quality parameters such as conductivity or TDS may not be variable enough to serve as stability indicators. An alternative is to characterize a well to determine the appropriate purge procedure for that well through multiple water quality or contaminant analyses during purging. Once the volume required to reach stability is determined, then that can be used for all subsequent sampling events if the sampling interval is properly isolated and the flow rate is controlled.

The highly transmissive nature of the saprolite-bedrock interface was confirmed by this study, and wells that are screened or packed within this zone are likely to intersect a major contaminant transport pathway. Strike-preferential flow is very apparent within this zone. Because of the high transmissivity and the different response times of various transport pathways to recharge events, reversals in transport direction can and do occur and can impact wells that are located upgradient for monitoring background concentrations. While these tend to be low flux transient events, these "background" locations can become contaminated over time by highly sorbing and/or highly toxic and very mobile contaminants.

The persistence of helium at nearly constant concentrations 19 months after tracer injection was terminated demonstrates the huge capacity of the porous matrix for storing and slowly releasing large masses of solutes, and the minimal effectiveness of matrix flushing even in the presence of large amounts of annual precipitation. Because of the large storage capacity 
of these fractured porous materials and the continuously changing groundwater dynamics, groundwater samples will be at varying degrees of equilibration with the surrounding matrix and will, therefore, be representative of varying mixtures of fracture and matrix waters. Both temporal variability and spatial variability should be taken into consideration in addition to the goal of the sampling when designing a sampling program and monitoring program. If a flux-weighted average is desired, then screened wells with large screened intervals that intersect multiple transport pathways should be used. Conversely, if groundwater contributions from multiple sources are to be understood, then multilevel wells should be installed based on the results of borehole investigations.

To address temporal variability, automatic sampling methods should be designed that allow flow-weighted sampling and storm sampling similar to the procedures used today for surface water sampling. The use of representative, low-cost analytes for estimating the total annual flux of contaminants should also be explored where relationships between contaminants and water quality parameters can be determined.

\subsection{MELTON VALLEY HYDROGRAPH ANALYSIS PROJECT}

(G. R. Moline, ORNL Environmental Sciences Division; W.B. Dress, ORNL Instruments and Controls Division; V. Federov and J.J. Beauchamp, ORNL Computational Mathematics and Physics Division; A. Woronow, University of Houston (currently at Exxon Production Research))

\subsubsection{Scope and Objectives}

The objectives of this project were to investigate the use of well hydrographs as indicators of subsurface hydrologic characteristics, and to construct a hydrodynamic model for Melton Valley based on the analysis of historical data. The project was motivated by the difficulty and costliness of obtaining direct measurements of hydrologic parameters such as hydraulic conductivity, effective porosity, fracture geometry, recharge, and evapotranspiration, particularly in a heterogeneous system where sparse information provides a poor picture of the overall dynamics of a region. The hypotheses were that (1) related data can be used to construct a three-dimensional picture of the dynamics that are controlled by those hydrologic parameters, and (2) the distribution and relative magnitude of these parameters can be estimated, and links to specific controlling mechanisms can be made. This project focused on the use of well hydrographs as indicators of local hydrologic properties, and included an analysis of nearly 500 wells and piezometers within Melton Valley on the Oak Ridge Reservation.

\subsubsection{Approach}

A three-phased approach was developed to test the hypotheses through analysis of the Melton Valley historical well data:

I. Establish hydrodynamic classes based on hydrograph characteristics for a subset of wells. 
The direct comparison of hydrographs from different years is complicated by changing meteorological conditions from year to year. To circumvent this problem, a three-year window from October 1, 1985 to October 1, 1987 was chosen in order to include a high density of daily water level measurements obtained during a USGS study conducted during this period. Thirty-seven wells completed at varying depths and distributed throughout Melton Valley were included in the classification subset according to the following criteria: the hydrographs must include daily water level measurements for a minimum of one full seasonal cycle within the 3-year window. In actuality, all of the hydrographs used were longer than one full year, and most were two years or longer. All hydrographs contained some data during the middle of the time window; extending the window to three years ensured the inclusion of a full seasonal cycle and maximized the data available for analysis, although it introduced some uncertainty due to differences in total precipitation for each of the three years. The wells were screened over a range of depths from 2 to $60 \mathrm{~m}$ and occur within all geologic units in the Conasauga Group.

From the data for the 37 wells, six grouping variables were determined: seasonal range, seasonal lag, seasonal recession slope, storm variance, storm lag, and storm correlation. Using these variables and a hierarchical clustering algorithm, seven hydrodynamic classes emerged. For each class, a "type" hydrograph was constructed by averaging the daily water levels for the hydrographs within each group.

II. Determine a set of mathematical functions that predict water level response to precipitation.

Three different approaches were used to develop mathematical functions for predicting hydrographs based on the corresponding precipitation record.

Neural Network: Use precipitation and a seasonal indicator as input data and use neural network algorithms to arrive at a system of nonlinear equations that produce the best estimate of the well hydrograph. The algorithm "trains" itself through iterative forward and inverse processes. The advantages are that the computation is very fast through the use of optimization techniques, and it allows the use of multivariate input functions. The primary disadvantage is that the nonlinear equations are buried within an algorithm and two sets of matrices that provide no means for linking the mathematical functions with formation characteristics.

Deconvolution: Use precipitation as input data and use deconvolutional algorithms to determine transfer functions that produce the best estimate of the well hydrograph. This approach is analogous to geophysical techniques for data analysis and signal processing, where the earth filters that translate a signal input consist of a set of linear or nonlinear equations that can be superimposed to predict the output. The advantages are that the equations derived have intuitive meaning that can potentially be related to formation characteristics such as hydraulic conductivity or fracture intersection, and the basis functions can predict an asymmetric waveform that matches the low frequency seasonal signal. The disadvantages are that it is time-consuming to determine the filters that will fit a particular 
hydrograph, as the user has to perform many forward iterations, and many coefficients are required to describe the hydrographs ( 32 for the current model).

Multiple Regression: Use precipitation and other meteorological data such as air temperature, barometric pressure, and relative humidity as input data and apply multiple regression (MR) methods to develop polynomial equations relating water level with meteorological data averaged over a range of time windows. The advantages are that the computations are relatively fast, the use of additional input data may allow modeling of the seasonal differences in recharge, and the algorithms can handle missing data, thus removing the errors incurred by interpolation. A disadvantage is that the physics relating the input signal to output response are not explicitly addressed and, thus, the equations are not intuitively linked to the hydrograph response. In addition, the use of sin and cos functions to predict the low frequency seasonal signal results in a symmetric wave function that does not match the asymmetric geometry of the data.

All models assume that:

1. The output response is a result of properties of the subsurface materials and natural processes that act upon the precipitation that has infiltrated between the time and location of infiltration and the time and location of arrival at the well screen. Any impact of varying well construction is small compared to formation effects, and all anthropogenic effects have been removed.

2. These properties and processes are time-invariant over the period of interest, so that a set of filters determined from one period of time should accurately predict the hydrograph for that same well for a different period of time using the input corresponding to that period.

\section{Use the mathematical functions to classifu the remaining hydrographs.}

Because the remaining hydrographs not included in the original subset were obtained over the timeframe of several decades and include observations at frequencies ranging from daily to monthly, it was necessary to have a mechanism for estimating the probable hydrograph response for each of the 7 dynamic groups for the meteorological conditions existing at those historical times. Then the unclassified hydrographs could be compared to the estimated hydrographs, and classified according to the best fit. In addition, the "goodness of fit" could be used to derive a probability that the classification is correct.

\subsubsection{Discussion}

The classification of hydrographs based on the 6 grouping variables chosen resulted in 7 dynamic groups or types of well response in which the similarity within groups was very 
good. The 6 variables were very poorly correlated, indicating that each was providing some unique information to the clustering algorithm. In addition, the grouping variables describe characteristics that have some intuitive meaning with respect to groundwater dynamics. No obvious correlations between the hydrograph classes for the subset of wells and possible controlling characteristics such as depth, topography, or geologic unit were identified. One potentially useful piece of information was obtained through examining hydrographs for several wells located in Bethel Valley. Wells located at or very near to a solution feature showed a very depressed response to all but the very largest storms and no seasonal response. As distance from the solution feature increased, so did both seasonal and storm responses, indicating the potential use of hydrograph responses for constraining the location of significant subsurface flow pathways.

Attempts to model the response to precipitation and other meteorological data provided mixed results. The neural net method (Model 1) performed well for estimating the hydrographs that contain a considerable storm response, and did increasingly worse for hydrographs with smoother responses. The model could not be trained to "ignore" high frequency changes in the input data for those wells that respond primarily to seasonal changes.

During development of the deconvolutional model, the test hydrograph was first evaluated using autocorrelation and cross-correlation methods. Significant periodic signals in the hydrograph data were identified and removed, leaving a purely storm-driven part of the signal. The periodic signals identified were an annual signal, two apparent harmonics of the annual signal, and, surprisingly, an earth tides signal. Once these low-frequency signals were removed, the residuals were cross-correlated with the precipitation data. The results clearly demonstrated a nonstationarity in the precipitation response that is linked to evapotranspiration (i.e., greater storm response during winter months). While this investigation was important for understanding the composition of the hydrograph signal, it could not be used to directly model a hydrograph response to a precipitation record. The final model was developed by creating basis functions that describe a composite seasonal signal derived from normalizing, phase-shifting, and combining all of the 37 hydrographs in the training set. These basis functions were then used to predict the seasonal component of each individual hydrograph by reapplying the scaling factors, producing a very good fit for the low-frequency seasonal component. A set of functions were then developed for predicting the storm response by applying a polynomial mapping process. This process produced predictions that captured many of the storm response characteristics, but contained significant errors due to nonstationarity and overestimation of the storm response for relatively smooth hydrographs. By incorporating additional meteorological parameters into the multiple regression method, it was hoped that the evapotranspiration effects could be accommodated. The seasonal signal was modeled as a sum of a sine and cosine function with appropriate lag. In order to keep the number of model parameters small, only the 10 most significant variables tested were retained in the final model. Results of the best model have errors in both seasonal and storm components. The periodic functions used to model 
the seasonal component produce only symmetric waveforms, while the data are quite asymmetric. In addition, the models have a mixture of over- and under-estimation of the storm response, although the addition of meteorological data does partially address the nonstationarity.

\subsubsection{Conclusions}

The methods and results are described in more detail in Moline et al. (1997, in prep.). In general, while some methods were better than others, none of the methods was able to fully accommodate seasonal differences due to changes in evapotranspiration ("nonstationarity"), and all tended to overestimate a response where the data are relatively smooth. Thus, the resulting or predicted hydrographs look more similar than their measured counterparts. In each case, the models produced a reasonably good prediction for the test hydrograph, but had less success in predicting other hydrographs with very different characteristics. Overall, the deconvolutional method provided the best estimation of the asymmetric seasonal patterns and the greatest amount of information that can be directly linked to physical mechanisms.

While the method shows great promise for use in determining the spatial distribution of subsurface hydrologic parameters, it still falls short of being applicable without a means for modeling the nonstationarity in the storm response due to evapotranspiration and without a model that allows better damping of storm response for those groups that are dominated by a seasonal signal. Thus it has not yet been applied to classifying the remaining Melton Valley hydrographs. It has illustrated that some very useful information such as EVT, specific storage, and distance to karst features or significant fracture flow zones can potentially be extracted from the decomposed hydrographs. These relationships will be explored in a more rigorous manner in the future. As a "quick-and-dirty" means for mapping regional groundwater dynamics, the method is still promising but requires further work.

\subsection{DEEP GW FLOW SYSTEM EVALUATION (R. Nativ (Hebrew University), G. R. Moline and C. T. Rightmire)}

Considerable effort has been spent over the past several years on studies to evaluate the deep groundwater flow system underlying the Oak Ridge Reservation. Because of the depths involved, the heterogeneous nature of the fractured rock system, a limited number of observation points, the nature of the brines and the general complexity of the system, the results to date are inconclusive. Detailed results of investigations that have been conducted on the deep groundwater flow system are summarized by Nativ, 1996, Nativ et al., 1997a and Nativ et al., $1997 \mathrm{~b}$.

Briefly, some of the salient findings are: The deep ground water system is confined to semi-confined, as indicated by observed barometric pressure responses. The slow recovery of water level in many deep boreholes (2-8 years) following their purging demonstrates restricted flow. The high salinity of the water could not have been preserved under 
intensive communication between shallow and deep groundwater systems. The ion ratios suggest the presence of residual brine, which may have been in the subsurface since the Paleozoic era. While mixing and subsequent dilution of the original brine with meteoric water provides an explanation for the observed brine compositions (Nativ, 1996), the presence of the residual brine signatures coupled with the high salinities indicate that mixing and dilution is a very slow process and that overall flux to the deep groundwater system is very small.

Fractures were observed at great depth in many cores. Temperature anomalies are associated with some of these fractures, suggesting that they may be hydraulically active. Dreier and Toran (1989) have suggested that those temperature anomalies result from deeper, hotter fluids moving upward along thrust faults. This conclusion was based on the high salinity and proximity to mapped faults at these locations. In some boreholes, flow in fractures was confirmed by flow meter measurements. Vertical flow between the deep and shallow hydrogeological systems seems possible under appropriate hydraulic conditions. Downward flow potential from the shallow to the deep system was documented in some of the wells completed in the Conasauga Group and confirmed by the presence of contaminated water at a depth exceeding $200 \mathrm{~m}$ (656 ft), or recent groundwater (with measurable tritium and a high percentage of ${ }^{14} \mathrm{C}$ ) at depths of up to $268 \mathrm{~m}(880 \mathrm{ft}$ ). However, there is the possibility that the presence of recent water or contamination in deep wells is an artifact of the drilling and well installation or, in the case of open boreholes, a result of borehole circulation and cross-contamination. An example is the tritium contamination in HHMS3A, which has dropped from $45,900 \mathrm{pCi} / \mathrm{L}$ in 1987 to $5800 \mathrm{pCi} / \mathrm{L}$ in 1996. This drop in concentration is more consistent with radioactive decay and diffusion into the surrounding matrix than with flushing by shallow groundwater, which would be expected to bring still more contamination into the wellbore. Upward flow potential from the deep hydrogeologic system into the shallow one is supported by an array of observations including salinity and temperature anomalies in the shallow system, vertical gradients in some well clusters in the Conasauga Group, and water levels measured below and above packed intervals in boreholes in the Chickamauga and Knox groups. The absence of saline springs on the ORR suggests that deep groundwater discharge is small enough that mixing and dilution with shallow groundwater along discharge pathways results in low salinity groundwater that in some cases retains deep groundwater signatures (e.g., Moline et al, 1998). Thus, while fluid potentials favor deep groundwater circulation, evidence suggests that the circulation is slow and the fluid volumes very small.

On the basis of the existing data, an interpretation of the deep groundwater system on the Oak Ridge Reservation may be summarized as follows: The deep hydrologic system contains confined to semi-confined brine, whose residence time in the subsurface is probably very long. The brine contained in the deep system originated from an evaporating water body, from which halite had precipitated. Whereas the salts in the Oak Ridge Reservation brine are therefore very old, a recent contribution of water is evidenced by the 
high percentage of modern carbon and tritium in the sampled saline groundwater. The modern water probably moves along a limited number of conductive fractures at relatively high velocities, but low volumes, in response to induced head conditions. The possibility exists that contamination observed in the deeper flow system could be attributed to induced flow resulting from purging and sampling wells in the low-permeability fractured rocks, or even from the process of well installation. It should be noted that several of the wells

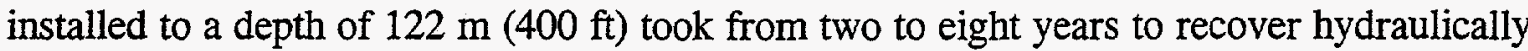
after installation. Diffusion of chemical constituents and the nonuniform mixing of fresh, recent water with the brine accounts for the large spatial and temporal variations in brine salinity. Deep groundwater discharge is probably through adjacent, more permeable units, where the brine is considerably diluted. The brine is not physically isolated from the overlying shallow system at all locations, and groundwater flow as well as solute (and contaminant) transport between systems can take place wherever pathways are naturally or artificially provided, but because of limited fracture aperture and density, the water volumes involved are likely to be small.

Although resources are not available at present, there is additional work that could be done to characterize the deep groundwater flow system on the Oak Ridge Reservation. The geometry of the deep hydrological system and the flow net within it have not yet been defined. The number of observation points and associated water chemistry data sets are insufficient to spatially map the top of the brine surface over space and time. The horizontal distribution of the brine and potential lateral flow pathways have not yet been assessed. The spatial distribution of major faults and fractures needs to be mapped, as they control the pathways and rate of solute/contaminant migration. The existing network of multiport wells, including many multiport wells that have been recently installed, is a valuable resource for further study of the deep system (e.g. hydraulic head and hydraulic conductivity values, chemical and isotopic composition) that should be incorporated in future studies designed to more conclusively resolve the quantities and extent of groundwater circulation in the deep system and whether flow of groundwater from the deep system to the shallow system represents a potentially significant pathway. In addition, work relating geologic structure, mechanical properties of rock units, and their relation to identified fracture networks, together with chemical characterization of groundwater from depths known to contain brine are needed to make further progress. 


\section{REMEDIATION TECHNOLOGY}

\subsection{CONSTRUCTED WETLAND DEMONSTRATION STUDY (A. J. Stewart)}

In early 1995, the Ground Water Program Office (GWPO) initiated a project to design, build and test a subsurface-flow constructed wetland (EPA, 1993) for treating water containing trichloroethylene (TCE). The key objective was to show that constructed wetland technology could be used to address specific clean-up or environmental compliance problems in a costeffective, scientifically sound, environmentally benign manner. The guiding technical principle to be shown was that levels of various aqueous-phase organic or inorganic pollutants can be reduced considerably by passing the contaminated water through a properly designed, microbially active, porous media (Kadlec and Knight, 1996; Moshiri, 1993; Hammer, 1989). The initial objective was to develop a mobile (trailer-mounted) system that could be used for rapid response at DOE-OR sites in dealing with small contaminated seeps. During the planning phase, the possibility of inadvertent releases of TCE from the unit to the environment due to spills, leaks or overflow events was recognized. It was also recognized that potential waste legacy issues would arise once TCE was passed through the system. Thus, several design features were incorporated to reduce risk of environmental contamination or human exposure to contaminants during wetland operation. These "add on" features increased the wetland's construction costs. To reduce costs, we also decided to demonstrate the system's ability to degrade a mixture of cresols (ortho- and meta-cresol), rather than TCE. Savings associated with the latter change were anticipated as a result of being able to use high-performance liquid chromatography (HPLC) conducted by an experienced student, rather than more expensive TCE analyses, and avoidance of TCE hazardous waste issues associated with the constructed unit at the end of the project.

By mid-December, 1995, wetland design and construction was largely complete. The constructed wetland "box" was deployed behind Building 1504, adjacent to an experimental ponds facility. Figure 5 shows the wetland unit during construction. The wetland itself consisted of a reinforced wood trough $1.8 \mathrm{~m}$ wide, $20 \mathrm{~m}$ long and $0.6 \mathrm{~m}$ deep, on short legs. It was double-lined with plastic, and was loaded with pea gravel to a depth of $0.4 \mathrm{~m}$. Water was pumped into the wetland from an adjacent pond to produce a saturated depth of $0.3 \mathrm{~m}$. Twelve species of emergent aquatic plants were planted in the wetland late December, so that they could initiate growth as early as possible in the spring (Sparks, 1996). The "subsurface flow, rock-reed system" wetland was fully operational, with running water, by the end of February, 1996.

In the spring of 1996, 23 piezometers (each a perforated length of PVC pipe, 3.5" diameter) were installed in the wetland so that conductivity of the water at different depths and locations could be measured by use of a probe-and-meter system. During the spring and summer of 1996, several plumbing modifications were made to enhance "fail safe" operation of the system in the event of pump failure on the downstream end of the wetland. With four part-time students assisting on the project to various degrees during the summer months of 

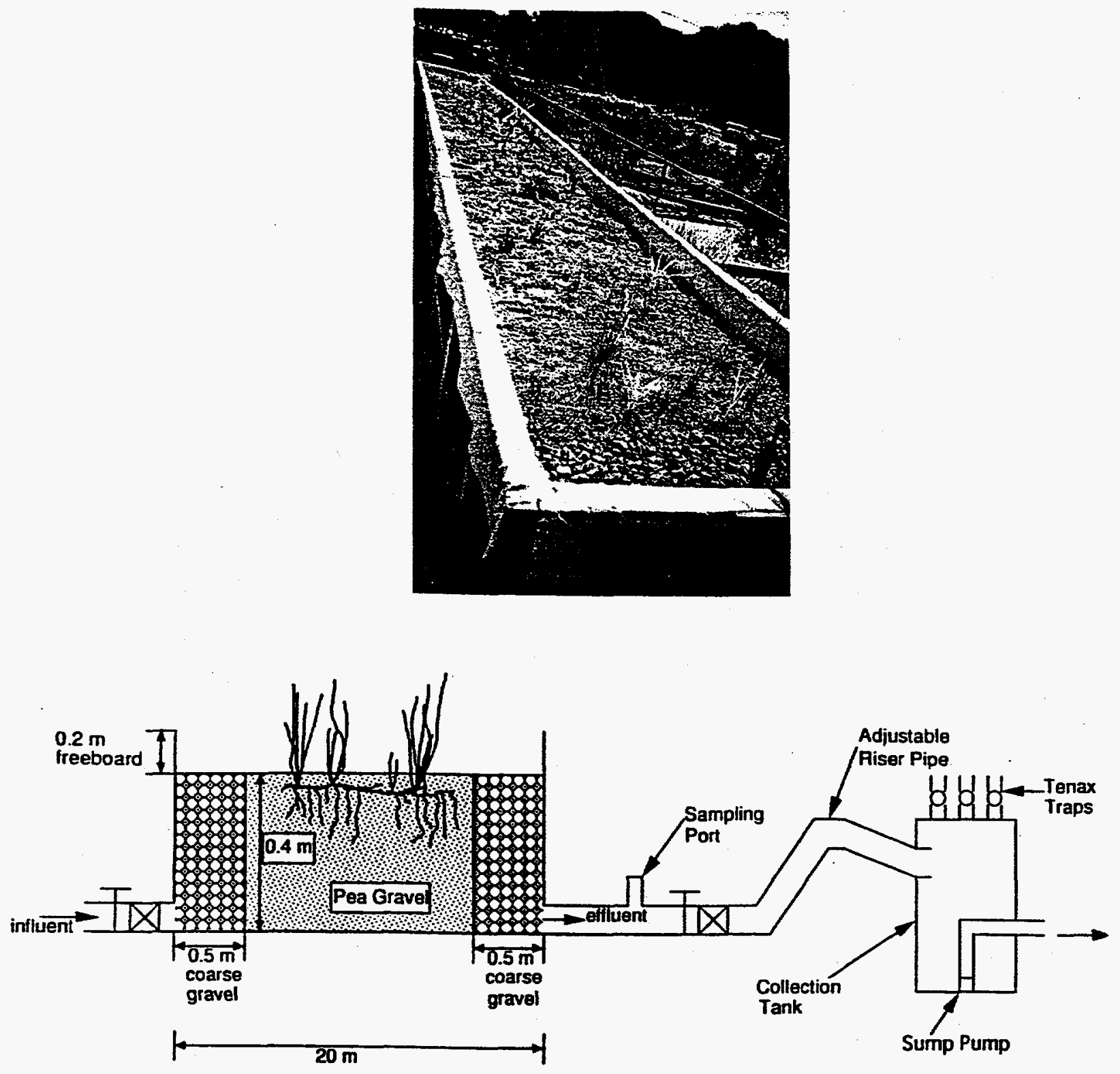

Fig 5. The wetland prototype during construction, prior to installation of piezometers. A version of this constructed wetland can be adapted to other locations where needed. 
1996, we determined water-temperature profiles in the piezometers and conducted several salt-release experiments. The objectives of these studies were to (1) assess variation in water flow-path patterns due to diel (i.e. chronological (24-hour) day) temperature changes in surface substrates versus substrates at depth, (2) determine the potential for "side-wall" effects of the wetland on plug-flow properties, and (3) obtain an empirical estimate for longitudinal dispersion as the salt "slug" moved through the system. Results are discussed in the following sections.

In June, 1996, with flow through the wetland at $3.87 \mathrm{~L} / \mathrm{min}$, water temperatures were measured at two depths in each piezometer $(10 \mathrm{~cm}$ and $30 \mathrm{~cm}$ depths $)$, and in the outlet standpipe. The data for this monitoring event are summarized in Table 1.

Table 1. Water temperature $\left({ }^{\circ} \mathrm{C}\right.$; mean $\bullet$ SD) in piezometers located in the upstream and downstream halves of a 20 -m long constructed wetland, at a depth of $10 \mathrm{~cm}$ (shallow) or 30 $\mathrm{cm}$ (deep) below the air-water interface. Means are based on 12 piezometers in the upstream half of the wetland, and on 11 piezometers (and an exit standpipe, functionally equivalent to a piezometer) in the downstream half of the wetland.

\begin{tabular}{lcc}
\cline { 2 - 3 } & $10-\mathrm{cm}$ depth & $30-\mathrm{cm}$ depth \\
\hline Upstream set of piezometers & $35.4 \pm 2.3$ & $30.0 \pm 2.8$ \\
Downstream set of piezometers & $39.5 \pm 1.0$ & $35.4 \pm 1.0$ \\
\hline
\end{tabular}

The top-to-bottom and upstream-to-downstream differences in water temperature appeared large enough to cause some degree of thermal stratification and thus, affect plug-flow characteristics. Several design and/or operational changes could reduce the development of thermal gradients, thereby providing opportunity for more controlled conditions for waste treatment. These changes include: use of lined, in-ground basins, rather than above-ground chambers, for holding wetland substrates, to take benefit of the thermal mass of the earth for temperature control; reducing substrate depth from $40 \mathrm{~cm}$ to $30 \mathrm{~cm}$; and decreasing the residence time of water in the wetland, by increasing the flow rate.

A salt-release study (6.3 L of 3-molar salt solution, administered at a rate of $25 \mathrm{~mL} / \mathrm{min}$ ), was initiated on August 5, 1996. At the end of the test, we found evidence for considerable "tailing" of salt at the upstream end of the wetland: conductivity in water at mid-depth in two piezometers near the far-upstream end of the wetland was still 2-3 times background. In an adjacent piezometer, conductivity of water at mid-depth was elevated more or less uniformly, 1.4-1.6 times normal background. We presume that this condition resulted from deviations from ideal plug-flow behavior; such deviations are common (Kadlec, et al., 1993). Factors contributing to these deviations in this study include the relatively low flow rate (1 gallon per minute) used in this test, and the tendency for different preferred flow-paths of the water due to diel changes in temperature. One implication of this outcome, for future studies 
with this wetland, is that first-order rate-constant calculations for contaminant degradation cannot be reliably based on plug-flow behavior (cf. Kadlec, et al., 1993). It is likely that use of higher flow-rates would lead to hydraulic behavior closer to ideal plug-flow.

In the final analysis, funding limitations and the associated reduced level of effort resulted in an inability to complete the proposed cresol-addition test, but an internship student identified methods suitable for the analysis of cresols by HPLC (Parris, 1984). During December, 1996, after the active project had ended, a freeze occurred before the drain pipes carrying water to the wetland were drained. This damaged several sections of pipe and destroyed the flow-meter used to regulate the rate of water addition.

There were at least four important "lessons learned" from the work conducted in this project:

- At least one full growing season is needed for effective establishment of aquatic plants in wetland systems such as the one described in this report.

- All of the plant species that we used in this study were able to survive in pea-gravel substrate.

- Rainfall events should be taken into account in the design phase for the water-handling system. We found that an expensive float-triggered sump pump was unable to keep up with rainwater inputs, given base-flow water-flow rates of $3.87 \mathrm{~L} / \mathrm{min}$, because wastewater line length and pipe diameter effectively limited the discharge.

- Use of an air-lift pump system, with a gravity-feed spigot from an overflow-protected headtank, may provide a more reliable means to establish a consistent flow of water to the wetland, and should be considered as an option for implementation where feasible.

The constructed wetland has served as a focal point for a number of tours and is a resource for familiarizing people with the concept and aiding visualization of how the design could be deployed. It continues to be included in external proposals for additional work and represents a useful starting point for future projects. In addition to the facilities themselves, which can be repaired and put into fully operational mode readily from the present "standdown" mode, a literature study did address the feasibility of using constructed wetlands for treating TCE (Sparks, 1996). Experience gained in this project also positioned us to assist in setting up and operating the constructed wetland facilities that were used to demonstrate nitrate and uranium removal from contaminated groundwater in Bear Creek Valley, near the Oak Ridge Y-12 Plant (SAIC, 1997), and to design and build a system of two wetlands, deployed near the ORNL coal yard runoff treatment facility. 


\subsection{PARTICIPATION IN WAG4 LOW-PRESSURE PERMEATION GROUTING PROJECT (D. D. Huff)}

Over the course of the past three years, there has been GWPO staff participation in an effort to demonstrate the utility of hydrologic source controls for managing radionuclide releases from the Oak Ridge National Laboratory's waste area grouping (WAG) 4. The underlying hypothesis was that contaminant sources are not uniform at WAG 4 (or other WAGs in Melton Valley), and that it is possible to pin-point and control the strongest sources to achieve reductions in releases in a cost-effective manner. Although much of the work was funded directly by Environmental Restoration, the overall progress to date would not have been possible without GWPO support. There have been three stages in the evolution of this work: The first part was a site investigation, using a variety of innovative tools that include remote sensing and GIS data synthesis, use of expedited site characterization methods that employed earth-penetration capabilities, coupled with small-diameter sampling wells and fast-turnaround radiochemical assays, application of noble gas tracing methods (developed in conjunction with the West Bear Creek Valley Tracer Test, discussed in Section 6.1), and shallow groundwater investigations combined with surface water hydrologic data collection and analysis. Application of models that were adapted for use at ORNL by other GWPO projects provided important forecasts of the expected time history of declines in releases that aided in acceptance of the approach. Details of all these tasks are presented in ORNL/ER329/V1\&V2, 1995, in Huff et al., 1996 and in Huff et al., 1997. The result of this stage was identification of portions of four waste trenches that together were responsible for over $70 \%$ of all ${ }^{90} \mathrm{Sr}$ releases from WAG 4 , and represent less than $1 \%$ of the total area.

The second stage of the WAG4 project was participation in field work that established a hydrologic baseline and provided technical guidance during the design and implementation of a low-pressure permeation grouting project. A description of the work is included in ORNL/ER-401/V1,V2 and V3. Final determination of exact trench locations, placement of multiple grouts to reduce hydraulic conductivity of the target trenches, and hydraulic testing of the resulting grout monoliths were achieved during this stage. In addition, methods were developed for evaluating the effectiveness of the grout in controlling releases by quantifying changes in releases in post-treatment runoff. These methods provided direct guidance for post-treatment monitoring.

The third stage of the project is ongoing. It involves monitoring for changes in radionuclide releases and evaluating the time history of the changes. Although data from only the first six months of post-grouting runoff are available, it is possible to say that model predictions match observed reductions in ${ }^{90} \mathrm{Sr}$ currently releases within expected bounds. Changes in the relationships between contaminant concentration and flow rate exhibit the most profound effects at the seep collection systems and for the highest flow rates, as expected. The delays between source reduction and the effect in the groundwater component of runoff, because

of travel time and attenuation between the source and the point where the water enters the surface water system, are also apparent in the results. At a monitoring site downstream of 
the treated area, releases of ${ }^{90} \mathrm{Sr}$ were reduced about $20 \%$ in the first six months, compared to base line conditions. At contaminated seeps, the corresponding reductions were about $60 \%$. A somewhat unexpected result is that tritium releases from the site appear to have declined by more than $60 \%$ during the first wet season following the grouting project. Although it is clear that the tritium releases near the target trenches were reduced by 70 $80 \%$, there were relatively minor tritium contributions from the areas that were grouted. However, a trench that was apparently the major contributor of tritium release for the site was under the gravel pad that was established for much of the operations and handling of supplies during grouting operations. It is speculated that the compaction resulting from heavy equipment operations, together with the capping effect from the pad have changed flow pathways in the vicinity of the tritium source, and as a result, the releases have declined. This result has important implications for control of tritium at other waste sites, since it appears to illustrate the importance of hydrologic controls for very mobile contaminants.

\subsection{ENVIRONMENTAL DECISION ANALYSIS}

\section{(B. R. James, D. D. Huff, J. R. Trabalka, R. H. Ketelle and C. T. Rightmire)}

Given the resource limitations for achieving environmental restoration objectives and the complexity of the hydrogeologic environment and nature of wastes at Oak Ridge sites, GWPO staff recognized the importance of practical tools to aid decision makers in carrying out their work. There were two major questions: How does one select the lowest total cost remedial action alternative from several feasible alternatives? and How does one decide whether or not to expend precious resources collecting more data? To address these questions, a small group of GWPO staff met over the course of several months to explore how economic-risk-benefit analysis could be applied to remediation decisions that lie ahead for the Oak Ridge Reservation. The objective was to develop a framework for evaluating complex remediation decisions that must weigh immediate action against the risk of waiting for better technology and resource availability, or the need to collect additional data. A related goal was to establish a framework for communicating the reasoning behind such decisions to the stakeholders and as a means for clarifying important objectives.

One question being debated at the time was whether the use of selective grouting for source control at ORNL's WAG4 was a better option than installation of a large cap-collect and treat system. Preliminary estimates for the capping option was roughly $\$ 10.5 \mathrm{M}$, while the grouting option was estimated at near $\$ 3 \mathrm{M}$. A simple way to look at the trade off is that if the grouting is selected, and fails to achieve the desired result, the cap-collect and treat option will then be required. If the probability of failure, $\mathrm{P}_{\mathrm{f}}$, can be estimated, along with the cost of failure, $\mathrm{C}_{\mathrm{f}}$, then the total cost of using the grouting option in this type situation can be estimated as the actual cost of grouting plus the product $\mathrm{P}_{\mathrm{f}} * \mathrm{C}_{\mathrm{f}}$. A simple plot, such as shown in Fig. 6, illustrates the break even point between using the grouting option versus the cap-collect and treat option in this case. 


\section{Remediation Cost Vs. Probability of Failure}

Cost of Failure

(\$ million)

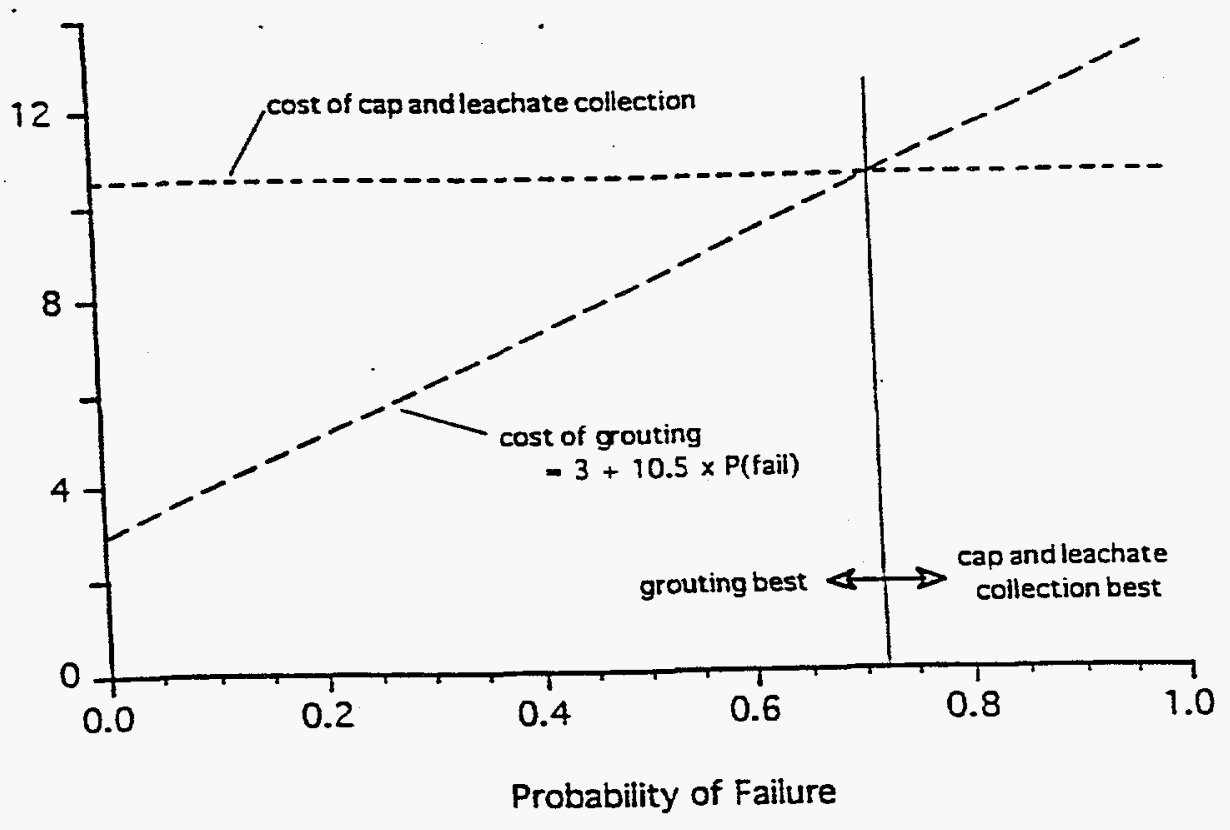

Fig 6. Decision analysis evaluation of the break-even point between grouting or cap, collect and treat options at WAG 4. 
The precise magnitude of the numbers is not as important as the realization that if the grouting has more than about a $30 \%$ chance of success, it is a better choice. Although this example is overly simplistic, it illustrates the value of the framework for putting decisions in perspective. Even with imperfect information on costs and probability of failure, some decisions are obvious at this level. In more difficult circumstances, further analysis is warranted. Regardless, the framework provides a useful way of communicating the risks and costs. A more rigorous explanation of the framework, together with a detailed application, has been published in the open literature (James, et al., 1996). 


\section{GWPO SITE SUPPORT AND INTERACTIONS \\ (C.T. Rightmire, A.F. Diefendorf, D.B. Watson, R.H. Ketelle, and T.Z. Zondlo)}

The nature of GWPO site support activities has evolved considerably during the FY95-FY97 period. During the early part of that period, the technical support representatives for each of the sites were funded primarily through the GWPO, with a broad mission to provide comprehensive review and support to a wide variety of groundwater activities at each site. As time progressed, there has been a shift toward incorporation of the technical support staff into specific projects at each site in the role of a technical advisor. This change in responsibility has necessarily involved a shift from a broad site-wide perspective toward more specific project goals, although some limited support from the GWPO resources has been available to allow interaction among each of the site support staff in the context of a broad program. As a result of these changes, the activities listed for each of the sites represent a blending of project activities and GWPO activities. The GWPO perspective is that it provided the framework and staff expertise that has evolved into the current arrangement, and thus shares responsibility for groundwater program activities at each of the sites. This, however, does not imply an attempt to take credit for the successful execution of site-specific projects. Rather, it is merely a recognition of a collaborative enterprise. Activities that highlight the major efforts over the past three years are summarized for groupings that range from all five sites to the Oak Ridge Reservation and to individual sites. These summaries are presented in the form of bulleted highlights.

\subsection{ALL SITES}

- Initiated a dialogue with Lockheed Martin Energy Systems risk assessors to attempt to reduce use of ultra-conservative assumptions for groundwater risk assessments by providing professional judgement and expertise in constructing scenarios.

- Developed a methodology that has been used for the establishment of reference values of naturally-occurring chemical constituents in groundwater.

- Focused attention on integration of industrial hydrogeology concerns (e.g. leaking water supply lines, sump pumping impacts on groundwater movement, etc.) into remedial studies and planning.

- Provided support to the Hydrology Subsection of the Site Technology Coordination Group. Helped establish site technical needs and made recommendations to DOE Technology Development.

- Provided technical reviews and support for the Office of the Chief Engineer/Geologist on numerous reports and technical matters. 
- Reviewed "Microwave technology demonstration project" and made recommendations for future work.

\subsection{OAK RIDGE RESERVATION SITES}

- Participated in planning sessions for the Integrated Water Quality Program. This involved a comprehensive review of all surface water and ground water monitoring sites to determine a minimum technically acceptable set of monitoring locations and analytes at several scales of spatial resolution.

- Participated in reviewing the Integrated Water Quality Program Plan. Pointed out limitations in the planned program and suggested needed revisions.

\subsection{EAST TENNESSEE TECHNOLOGY PARK}

- Provided technical leadership in development and publication of the K-25 Remedial Studies Evaluation Report (RSER)

- Promoted development of an extensive characterization of karst features, including springs and seeps, together with studies of interactions between the K-25 ground water system and the Clinch River, which exhibits considerable fluctuations in water stage.

- Identified the importance of the storm drain system in controlling and integrating ground water discharge from the near-surface portion of the saturated zone. This recognition provided the basis for cost-effective design of water quality monitoring for a portion of the system.

\section{$8.4 \mathrm{Y}-12$}

- Promoted technical demonstration projects for reactive barrier technologies to control shallow subsurface contaminants in ground water.

- Provided technical leadership in developing Bear Creek Valley watershed conceptual model for contaminant fate and transport and preperation of the RI report. The State provided a letter of commendation on the RI Report. An excerpt follows:

"The State would like to commend all those responsible in the production of the BCV RI Report for their effort in producing a well written, clear, concise, and thorough document. This holistic approach will greatly benefit the implementation of realistic and appropriate remedial actions in Bear Creek Valley." 
- Developed approach and provided direction for groundwater modeling of the BCV and UEFPC watersheds.

- Promoted technical demonstration projects for passive treatment barrier technologies at the S-3 Ponds site to control migration of contaminated groundwater to nearby tributaries. Provided technical leadership on two EM-50 projects and one EM-40 project that were funded and succesfully identified contaminant transport pathways and treatment options (potentially saving millions of dollars over conventional pump and treat).

- Provided technical leadership on all aspects of the UEFPC Watershed Project including:

- Evaluation of extensive existing data and development of conceptual models

- Development of "Key Questions" that focussed the R/FS on critical data collection needs

- Coordination of technical presentations on existing data to the "Core Team" consisting of DOE, TDEC, and EPA. The "Core Team" used this information to develop a list of data gaps to be filled during the $\mathrm{RI}$ and a list of likely actions for each source area.

- Preparation of the RI Report

- Identified the importance of hydraulic controls on migration of the Union Valley carbon tetrachloride plume, and of the changing migration pathways in response to closure of New Hope Pond, installation of the UEFPC underdrain and pumping in the vicinity of Lake Reality.

- Identified discharge points for the offsite Union Valley plume by field locating and sampling seeps and springs in Union Valley and mapping Rogers Group Quarry. Identified groundwater and surface water users in Union Valley and helped to determine the extent of the area covered by the Union Valley IROD that requires DOE notification prior to any change in groundwater use.

- Participated on a team that identified data quality issues related to the groundwater radiological data being collected at Y-12. Selected BCV and UEFPC wells that were sampled as part of a special radiological sampling program. Participated on a Performance Measurement Team (PMT) that assessed radiological sampling and analysis procedures for the ORO.

- Participated on a team that developed groundwater background values for Y-12. 


\subsection{ORNL}

- Provided Environmental Restoration with Technical Lead staff for ground water investigations and remediation planning (K-25 RSER, Y-12 UEFPC Watershed RI/FS, ORNL WOC Watershed RI/FS)

- Provided technical support to the ORR Resource Management Office for ground water issues and concerns.

- Arranged for a comprehensive seeps and springs survey for the Oak Ridge Reservation to further characterize flow systems and transport pathways.

- Provided technical support to DOE-ORO in evaluating and eliminating pumping of ground water at Parcel A2. This action prevented undesirable induced migration of the Union Valley carbon tetrachloride plume and potential comingling of wastes from the long-since closed Oak Ridge City landfill.

- Worked with the ORNL Environmental Restoration Program to develop a comprehensive watershed approach for Remedial Investigations and contributed to an $\mathrm{RI}$ report for the Melton Valley portion of the White Oak Creek watershed.

- Collaborated on the ORNL WAG 4 site investigation, evaluation and subsequent planning for interim measures to control radionuclide releases in ground water and surface water.

- Provided guidance to DOE-ORO for siting of a cryogenic barrier demonstration project, which has been implemented at the Homogeneous Reactor Experiment Pond site.

- Developed a surface water montoring methodology and strategy for evaluating effectiveness of remedial actions for source control actions.

\subsection{PADUCAH}

- Recommended against the pump and treat pilot remediation for the NW plume at PGDP in favor of implementing a site-wide barrier wall with internal hydraulic control for controlling organic solvent and radionuclide contaminant migration. The recommendation was not adopted, but it still merits further consideration

- Initiated an analysis of the groundwater system at PGDP to show the importance of artificial recharge on the shape of the NW and NE contaminant plumes. Noted that elimination of the leakage that provides the recharge would result in changing the 
plume shape and direction and probably degrade the effectiveness of current pump and treat wells. This issue is currently being evaluated.

- Recommended elimination of costly infiltration systems for NE plume pump-and-treat facility. Efforts received Columbus Initiative award.

- Initiated analyses of groundwater recovery well water to demonstrate that metals plumes do not exist at Paducah and costly sampling and analysis could be minimized.

- Conducted a detailed evaluation of soil and groundwater chemistry at Paducah (Moore, 1995)

- Recommended completion of WAG6 Characterization prior to commitment to remedial technologies. The recommendation was not adopted, and commitments were made without full characterization information.

- Continued to provide reviews and comments and participate in all DQO sessions, Work Plans, RI's, FS's, treatability studies and comment resolution meetings.

- Strongly recommended containment as a primary source-control technology, coupled with other source reduction technologies.

- Initiated and facilitated a Groundwater Modeling Committee for PGDP to eliminate costly duplication of modeling efforts and to achieve agreement on code selection and input parameters by all contractor, DOE and regulatory parties.

- Provided guidance and support for obtaining aerial photography and revised digital elevation data for PGDP.

\subsection{PORTSMOUTH}

- In conjunction with PORTS GWPP determined ineffective X-701B closure activities associated with soil mixing technology which was ineffective under the conditions encountered.

- PORTS soil and groundwater background study. Using techniques developed at the Y12 and Paducah Plants, and at the K-25 Site, a study using available PORTS data was conducted to determine background or reference concentrations on soils and groundwater. The results of the study are under a PORTS management review, but the remediation savings that could result from this study could be in the tens of thousands to hundred of thousands of dollars. 
- Assessment of the likelihood of metals plumes at PORTS. Using available data, a management decision framework was developed that could assist PORTS management assess the likelihood of dissolved metals contaminated plumes on site. At those locations where a metals plume could exist, the same decision framework could be used to assist management decide what wells to sample to validate or confirm that a metals plume is actually a problem.

- Proposal to modify and consolidate groundwater monitoring requirements. GWPO provided time-critical technical support to meet a corporate milestone and achieve a Columbus Initiative for the PORTS site. This innovative proposal advocates that common sense and technical consistency be applied comprehensively to the PORTS groundwater sampling program. The proposal establishes criteria that would assure that groundwater sampling locations, frequencies, and analytical methods implemented at PORTS are cost-effective and meet DOE regulatory and technical needs. In laboratory cost alone, it is estimated that the proposal could save DOE over $\$ 800,000$ over the period 1997 to 1999.

- Fiscal Year 1997 ITO technical assistance. GWPO provided time-critical technical support to PORTS in writing its Fiscal Year 1997 Incentive Task Order.

\section{COMBINATION OF R\&D AND SITE NEEDS}

As individual site issues have been identified in the course of conducting GWPO activities, there has been a corresponding response in the direction of research and development projects to provide information that can be used to guide decision making on solutions. In the following examples, there is a brief description of the issue, followed by a summary of the research and development that was conducted to address the questions. Finally, the conclusions that have been reached are described. The intent is that the discussion and conclusions will provide a useful base to guide overall strategy and avoid unproductive approaches to solving environmental restoration challenges in the future.

\subsection{DENSE NON-AQUEOUS PHASE LIQUID (DNAPL) CONTAMINATION}

At nearly all DOE-ORO sites, significant quantities of organic solvents were used and disposed, often in land-farming type operations. Where these solvents were DNAPLs, the free product moved into the saturated aquifer or aquitard system by virtue of being more dense than water. The final depth of penetration depended on the quantity of DNAPL disposed and local geologic conditions (e.g. presence of fractures and/or structures that trapped the material and prevented further migration). Questions associated with this type of contamination include: Can the residuals be located? How persistent is resulting groundwater contamination? Under what conditions are groundwater pump and treat remediation projects appropriate? 
Conditions on the Oak Ridge Reservation represent particularly challenging technical issues for answering these questions. Because of the presence of fractures that represent major flow pathways in media that have low matrix permeability but high porosity, physical diffusion (termed matrix diffusion) of the solvents into the inactive pore spaces of the aquifer material is believed to have a profound effect on the mobility of the contaminants, both free product and the portion that dissolves into and thus contaminates groundwater. To allow technically defensible estimates of persistence, it was necessary to demonstrate the importance of matrix diffusion, and provide sufficient characterization of the process to allow numerical models of transport to be developed and tested. A variety of projects were conducted to accomplish this task (Noble gas tracer test, Studies of matrix porosity, Evaluation of long-term tritium tracer tests, Relation between geology and fracture patterns and a suite of model development and application projects).

Several important conclusions resulted from these projects. Perhaps one of the most important is that simple pump and treat projects to remove DNAPL contamination from the ORR aquitards would require flushing of the contaminated zone by many pore volumes of water, which would take centuries to complete and be tremendously expensive. It is possible to use hydraulic controls, like a well or sump that is pumped, to contain the secondary contamination released into the groundwater, but unless this is combined with some other means of containing or destroying the primary source, such controls would have to be maintained for the indefinite future. Another result that is important for the ORR aquitards is that the fracture network that is present in the geologic materials plays a dominant role in controlling the rate and direction of groundwaterflow and contaminant migration. Actual flow pathways result from a combination of local hydraulic head (driving potential) and fracture networks. This is important for both monitoring system design as well as locations for treatment systems.

\subsection{THE IMPORTANCE OF KARST (CARBONATE ROCK) FEATURES ON THE ORR}

It is well known that the carbonate rock units on the ORR contain solution features (e.g. sinkholes, resurgent springs, caves and mud-filled conduits). For these geologic units, groundwater flow can be greatly influenced by the karst features, and conventional watershed considerations for flow pathways may not apply. Thus it is important to know the locations of geologic units that are susceptible to karst development, where potential discharge springs are located, and how the potential contaminant pathways associated with karst features behave for purposes of monitoring.

The geologic units most susceptible to karst features are the Knox and Chickamauga Groups. More than $90 \%$ of the sinkholes found on the ORR occur within the Knox Group and the remainder occurs within the Chickamauga Group (Lemiszki, et al., 1997). Systematic fractures in the carbonates are planar, have relatively long lengths, and maintain a fairly consistent orientation with respect to bedding planes. All of the caves on the ORR occur 
within the Knox Group or Maynardville Limestone. Portions of all three of the DOE facilities are underlain by carbonate rock units, and where this occurs it is important to know the location of these units in relation to potential contaminant sources, as well as the most likely groundwater discharge points for these units. For example, at ORNL, a carbonate rock unit that has known solution features underlies waste area grouping (WAG) 3 . Even though drainage from WAG 3 would be expected to discharge into the Whiteoak Creek watershed, it has been demonstrated that a groundwater discharge pathway to the Raccoon Creek watershed (under a surface water divide) exists in conjunction with this geologic unit. Similarly, at Y-12, karst features associated with the Maynardville Limestone have been shown to be responsible for a groundwater flow pathway along Union Valley, in an easterly direction from the DOE facility. At ETTP, carbonate rocks under that facility also display karst features. The GWPO has encouraged development of tracer techniques to allow characterization of the locations of karst flow pathways and also to help quantify contaminant transport rates in such features. Maps of sinkholes, springs and cave locations, together with comprehensive geologic mapping of bedrock units provides information on potential pathways and discharge points (for addressing exit pathway concerns).

The important inferences from the research and development work that has been sponsored by GWPO include the identification of major subsurface contaminant pathways, and the knowledge that contaminant migration can range from fairly steady concentrations to highly transient fluctuations associated with storm events. Knowledge of the most likely pathways and groundwater discharge points has been instrumental in designing monitoring strategies that give maximum assurance that contaminant releases will not go undetected. This knowledge was also used to make an important recommendation, which DOE adopted, to include groundwater use restrictions in the deed when a portion of ORR land was released for development. The events since that time have shown that without that recommendation, groundwater would have been developed, and a significant potential for induced migration of contaminants would have been created.

\subsection{BACKGROUND WATER CHEMISTRY}

Knowledge of background groundwater chemistry is essential to detecting the presence of contaminants, yet many contaminated sites on the ORR are located where up-gradient sampling of groundwater is physically not possible because the waste sources are on groundwater divides. Further, it is recognized that concentrations of water-quality constituents in groundwater are log-normally distributed, and it is important to have a measure of natural variability to avoid false positive detection of contamination, which can lead to costly and unneeded investigations.

Through a methodology that uses statistical analysis of all available water chemistry data for a given site, it has been possible to develop an approach for determining the statistical distribution of individual water-quality constituents in ground water. This methodology has been applied to many of the DOE-ORO sites. By making maximum use of existing 
monitoring well data, this approach reduces the necessity for added background wells and provides a more representative picture of natural variability of ground water chemistry.

The background groundwater quality determination methodology has been an important contribution to site groundwater program planning and management. It has made it possible to identify the statistical distributions of individual groundwater-quality constituents and thus provide a sound basis for evaluation of water quality data from individual wells for presence of contamination. In some cases, even though water quality constituents exceed drinking water guidelines (an often used criteria for presence of contamination), it has been possible to show that observed concentrations are within the normal variability expected for site geochemistry. This knowledge is valuable in decision making about whether treatment of the groundwater is necessary or appropriate.

\subsection{SAMPLING PROTOCOL}

Most of the DOE-ORO facilities have a large number of monitoring wells, and a correspondingly large effort in sampling and analyzing the groundwater chemistry at these wells. On the Oak Ridge Reservation, many of these wells are located in low-permeability, fractured rock systems, where sampling activities may be time consuming and costly because of conventional purge requirements to obtain representative samples of the groundwater. However, extraction of relatively large volumes (three well-bore volumes) of purge water not only is time consuming and expensive (because of labor requirements), but also results in large volumes of purge water that must be treated. In addition, extraction of large quantities of water from the ORR aquitards may induce transport of contaminants over large distances and result in a distorted picture of contaminant distribution.

Evaluation of sampling protocols has shown that the most representative samples can be obtained by low flow micro purge techniques that employ in-line monitoring to indicate when stable water quality conditions have been met. It has also been shown, using the colloidal bore-scope, that when a pump is introduced into a well for monitoring purposes, the disturbance will persist for up to 24 hours, and water quality measurements will be suspect during that period. As a result of this understanding, monitoring programs have shifted to dedicated sampling systems that employ a low-flow micropurge technique for collecting groundwater samples. By using dedicated samplers, disturbances to water quality and costs associated with cleaning of equipment between individual wells have been avoided. Further, by using packer systems that isolate the sampling interval within the well, the volume of water that must be removed before water chemistry stabilizes during sampling is minimized. Also, by using a very low-flow sampling rate, representative samples can be obtained without major distortions to the groundwater flow system. The result is much more cost-effective and efficient sampling, and more consistent and reliable sampling results. 


\section{REFERENCES}

Clapp, R.B., Estimating Groundwater Recharge to the Shale Aquifers in Eastern Tennessee using a Topography-Based, Water-Budget Model, in Extended Abstracts from Seventh Tennessee Water Resources Symposium, Maxwell House Hotel, Nashville, Tennessee, February 24-26, 1997, pp 151-153.

Dorsch, J., Determination of Effective Porosity of Mudrocks - A Feasibility Study, ORNL/GWPO-019, November, 1995.

Dorsch, J. and T.J. Katsube, Effective Porosity and Pore-Throat Sizes of Mudrock Saprolite from the Nolichucky Shale within Bear Creek Valley on the Oak Ridge Reservation: Implications for Contaminant Transport and Retardation Through Matrix Diffusion, ORNL/GWPO-025, May, 1996.

Dorsch, J. T.J. Katsube, W.E. Sanford, B.E. Dugan, and L.M. Tourkow, Effective Porosity and Pore-Throat Sizes of Conasauga Group Mudrock: Application, Test and Evaluation of Petrophysical Techniques, ORNL/GWPO-021, April, 1996.

Dreier, R.B. and L.E. Toran, 1989. Hydrogeology of Melton Valley determined from head measuring station data. Oak Ridge National Laboratory, Oak Ridge, TN. Environmental Sciences Division Publication No. 2836. ORNL/TM-11216.

Dugan, B.E., 1996. Characterizing the saprolite-bedrock transition zone at a study site on the Oak Ridge Reservation. Unpublished honors thesis, University of Minnesota.

Environmental Protection Agency. 1993. Subsurface Flow Constructed Wetlands for Wastewater Treatment: A Technology Assessment. EPA 832-R-93-008. Municipal Technology Branch (WH 547) U.S. Environmental Protection Agency, Washington, DC.

Gierke, W.G., W.B. Lozier, and R. Pearson, 1988. Task 2, well logging and geohydrologic testing, site characterization and groundwater flow computer model application, Vol.1. Golder Associates, Inc., ORNL/Sub/30X-SA706C.

Hammer, D. A. (ed.). 1989. Constructed Wetlands for Wastewater Treatment. Lewis Publishers, Chelsea, Michigan. $831 \mathrm{p}$.

Hatcher, R.D., P.J. Lemiszki, R.B. Dreier, R.H. Ketelle, R.R. Lee, D.A. Leitzke, W.M. McMaster, J.L. Foreman, and S.Y. Lee. 1992. Status report on the geology of the Oak Ridge Reservation. ORNL/TM-12074. Oak Ridge National Laboratory, Tennessee. 
Huff, D.D., J.D. Long and A.A.M.C. Naudts, Demonstrating the Utility of Grouting for Radioactive Waste Source Control, in Extended Abstracts from Seventh Tennessee Water Resources Symposium, Tennessee Section of the American Water Resources Association, Maxwell House Hotel, Nashville, Tennessee, February 24-26, 1997.

Huff, D.D., J.D. Long and A.A.M.C. Naudts, Radwaste Source Control by Surgical Strike -A Cost-Effective Strategy, Radwaste Magazine, Vol 3 (6), pp 20-26, November, 1996.

James, B.R., D.D. Huff, J.R. Trabalka, R.H. Ketelle, and C.T. Rightmire, Allocation of Environmental Remediation Funds Using Economic Risk-Cost-Benefit Analysis: A Case Study, Groundwater Monitoring and Remediation, Vol 16 (4), pp 95-105, Fall 1996.

Jones, T.L., L.E. Toran, D.B.Watson, 1996. Variable-density flow and transport modeling to evaluate anomlaous nitrate concentrations. ORNL/GWPO-0024

Kadlec, R. H., W. Bastiaens, and D. T. Urban. 1993. Hydrological design of free water surface treatment wetlands. Pp. 77-86. IN: Moshiri, G. A. (ed.). Constructed Wetlands for Water Quality Improvement. Lewis Publishers, CRC Press, Boca Raton, Florida. 632 p.

Kadlec, R. H. And R. L. Knight. 1996. Treatment Wetlands. Lewis Publishers, CRC Press, Boca Raton, Florida. 893 p.

Ketelle, R.H., and R.R. Lee, 1992. Migration of a Groundwater Contaminant Plume by Stratabound Flow in Waste Area Grouping 1 at Oak Ridge National Laboratory, Oak Ridge, Tennessee, ORNL/ER-126, Oak Ridge National Laboratory, Oak Ridge, Tennessee.

Lemiszki, P.J., Mesoscopic Structural Analysis of Bedrock Exposures at the Oak Ridge K-25 Site, Oak Ridge, Tennessee, K/ER-259, July, 1995.

Lemiszki, P.J., B.A. Zerr, and R.J. Sepanski, A Karst Inventory of the Oak Ridge Reservation, Tennessee, in Extended Abstracts from Seventh Tennessee Water Resources Symposium, Tennessee Section of the American Water Resources Association, Nashville, TN, February 24-26, 1997, pp 84-91.

Lockheed Martin Energy Systems, Inc. Groundwater Program Office Annual Report for Fiscal Year 1994, ORNL/GWPO-013, September, 1994, p 72.

McKay, L.D., P.L. Stafford, L.E. Toran, in press. EPM modeling of a field-scale tritium tracer experiment in fractured, weathered shale. Ground Water.

Moline, G.R., R.S. Burlage, L.D. McKay, J.M. Strong-Gunderson, W.E. Sanford, A. Harton, and D. Cumbie, in preparation. Determining fracture connectivity in a weathered shale saprolite from pumping and tracer tests. For submission to Water Resources Research. 
Moline, G.R., W.B. Dress, A. Woronow, V. Federov, and J.J. Beauchamp, in preparation. An evaluation of methods for predicting groundwater dynamics from meteorological data. For submission to Mathematical Geology.

Moline, G.R., C.R. Knight, and R. Ketcham, 1997. Quantifying sorption and matrix diffusion in a fractured shale saprolite using multiple tracers. EOS, V.78, No. 46 supplement, p.F330.

Moline, G.R., W.E. Sanford, R.S. Burlage, J.M. Strong-Gunderson, D. Cumbie, A. Harton, and L.D. McKay, 1995. Assessing fracture interconnectivity and fracture flow dynamics using multiple groundwater tracers: EOS, Transactions of the American Geophysical Union, v. 76(46), p. F239.

Moline, G.R., and M.E. Schreiber, 1995. Summary of FY94 Site Characterization and Installation of Multilevel Wells at a West Bear Creek Valley Research Site on the Oak Ridge Reservation. ORNL/TM-13029, Oak Ridge National Laboratory, Oak Ridge, TN.

Moline, G.R., and M.E. Schreiber, 1996. Summary of FY94 Site Characterization and Installation of Multilevel Wells at a West Bear Creek Valley Research Site on the Oak Ridge Reservation. ORNL/TM-13029, Oak Ridge National Laboratory, Oak Ridge, TN.

Moline, G.R., M.E. Schreiber, and J.M. Bahr, 1998. Designing appropriate sampling protocols for fractured media. J. Env. Engineering, in press.

Moore, G.K., 1988. Concepts of Groundwater Occurrence and Flow Near Oak Ridge National Laboratory, Tennessee. ORNL/TM-10969, Oak Ridge National Laboratory, Oak Ridge, TN.

Moore, G.K., and S.C. Young, 1992. Identification of Groundwater-Producing Fractures by Using an Electromagnetic Borehole Flowmeter in Monitoring Wells on the Oak Ridge Reservation, Oak Ridge, Tennessee. ORNL/ER-91.

Moore, G.K., 1995. Inorganic Soil and Groundwater Chemistry Near Paducah Gaseous Diffusion Plant, Paducah, Kentucky. ORNL/TM-1289.

Moshiri, G. A. (ed.). 1993. Constructed Wetlands for Water Quality Improvement. Lewis Publishers, CRC Press, Boca Raton, Florida. 632 p.

Nativ, R., 1996, The brine underlying the Oak Ridge Reservation, Tennessee Characterization, genesis and environmental implications. Geochimica and Cosmochimica Acta. v. 60 , pp. $787-801$. 
Nativ, R., A.L. Halleran and A.E. Hunley, 1997a, The Deep Hydrogeologic Flow System Underlying the Oak Ridge Reservation--Assessing the Potential for Active Groundwater Flow and Origin of the Brine, ORNL/GWPO-018, Oak Ridge National Laboratory, Oak Ridge, Tennessee.

Nativ, R., A. Halleran, and A. Hunley, 1997b, Evidence for Ground-Water Circulation in the Brine-filled Aquitard, Oak Ridge, Tennessee. Vol 35, No 4, Ground Water, pp 647 - 659.

O'Brien, P.M. Jardine, J.P.Gwo, L.D. McKay, and A.D. Harton, in prep. Experimental and numerical evaluation of solute transport processes in fractured saprolites. Submitted to Water Resources Research.

ORNL/ER-329/V1\&V2, Site Investigation Report for Waste Area Grouping 4 at Oak Ridge National Laboratory, ORNL Environmental Restoration Program, Oak Ridge, Tennessee, August 1995.

ORNL/ER-401/V1,V2 \& V3, Field Grouting Summary Report on the WAG 4 Seeps 4 and 6 Removal Action Project, Oak Ridge National Laboratory, Oak Ridge, Tennessee, ORNL Environmental Restoration Program, Oak Ridge, Tennessee, May, 1997.

Parris, N.A. 1984. Instrumental liquid chromatography: a practical manual on highperformance liquid chromatographic methods. Second edition. Journal of Chromatography Library, vol. 27, Elsevier, New York.

Reeves, M., 1996. Review of T2VOC with comparisons to UTCHEM and other NAPL simulation models. Letter report from Intera, Inc, Austin, TX to Environmental Sciences Division, Oak Ridge National Laboratory.

Sanford, W. E., Jardine, P.M., and Solomon, D.K., 1994. Examining matrix diffusion in fractured shales with noble gases. In: Geological Society of America Annual Meeting, Seattle, A-362.

Sanford, W.E., and G.K. Moore, 1994. Measurement of specific discharge with pointdilution tests in the fractured rocks of eastern Tennessee: Proceedings of Extended Abstracts, American Water Resources Association 1994 Annual Spring Symposium, Nashville, TN, pp. 449-453.

Sanford, W.E., Shropshire, R.G., and Solomon, D.K. (1996). "Dissolved gas tracers in groundwater: simplified injection, sampling, and analysis". Water Resources Research, vol. 32 , no. 6 , p.1635-1642. 
Sanford, W.E. and Solomon, D. K., 1995. Noble gas tracer experiment in a fractured weathered shale near Oak Ridge, Tennessee. In: Proceedings of the International Association of Hydrogeologists, Solutions' 95 Congress in Edmonton, Alberta, Canada, p. 5.

Sc̀hreiber, M.E., 1995. Vertical Variability in Groundwater Chemistry in Fractured Media: Results from a Field Experiment in the Nolichucky Shale, Oak Ridge Reservation, Oak Ridge, TN. Unpublished MS thesis, University of Wisconsin - Madison, Madison, WI.

Schreiber, M.E., G.R. Moline, and J.M. Bahr, (1997) in revision. Geochemical indicators of transport dynamics in a fractured shale: submitted to Applied Geochemistry, accepted pending revision.

Science Applications International Corporation. 1997. Phase I Report on the Bear Creek Valley Treatability Study, Oak Ridge Y-12 Plant, Oak Ridge, TN. Y/ER-285. Office of Scientific and Technical Information, Oak Ridge, Tennessee.

Solomon, D. K., Cook, P. G., and Sanford, W. E., 1997. Dissolved Gases in Subsurface Hydrology, Chapter $10 \mathrm{In}$ : C. Kendall and J. McDonnel (eds.), Isotope Tracers in Catchment Hydrology, Elsevier, in press.

Solomon, D.K., G.K. Moore, L.E. Toran, R.B. Dreier, and W.M. McMaster, Status Report A Hydrologic Framework for the Oak Ridge Reservation, ORNL/TM-12026, Energy Systems Oak Ridge Hydrology Support Program, Oak Ridge, Tennessee, May, 1992.

Sparks, B. J. 1996. Constructed wetlands for trichloroethylene (TCE) treatment. Independent study report for partial fulfillment of master's degree, University of Tennessee Department of Civil Engineering. $47 \mathrm{p}$.

Stafford, P.L., L.E. Toran, L.D. McKay, in press. Influence of fracture truncation on dispersion: A dual permeability model. Journal of Contaminant Hydrology.

Tucci, P., Hydrology of Melton Valley at Oak Ridge National Laboratory, Tennessee, U.S. Geological Survey Water-Resources Investigations Report 92-4131, Nashville, Tennessee, 1992.

Webster, D.A. 1996. Results of Ground-Water Tracer Tests Using Tritated Water at Oak Ridge National Laboratory, Tennessee. U.S.G.S Water-Resources Investigations Report 954182 .

West, O.M. and Toran, L.E., 1994. Development of a three-dimensional groundwater flow model for western Melton Valley: Application of P-FEM to a DOE waste site. ORNL/TM12474 
Yang, Z., R.S. Burlage, W.E. Sanford, and G.R. Moline, 1996. DNA-labeled silica microspheres for groundwater tracing and colloid transport studies: Proceedings, 212th National Meeting, American Chemical Society, Orlando, FL, Aug. 25-30, 1996. 
APPENDIX A 


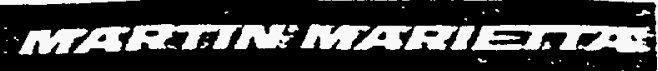

Internal Correspondence

MARTIN MARIETTA ENERGY SYSTEMS. INC.

Date: $\quad$ August 21, 1995

To:

C. T. Rightmire

cc:

J. E. Powell, D. A. Stephenson, W. B. White,

From:

L. W. McMahon, 9116, MS -8089 (4-7535)

L. Way m M"noliw

Subject: The 1995 Report of the Groundwater Program Office (GWPO) Advisory Committee

The Advisory Committee for the GWPO conducted its review on July 26-27, 1995 and is providing via this memo a final report and recommendations for 1995 .

On behalf of the Committee, please express our thanks to the participants for their candid input and their diligence in tackling the technical and administrative issues associated with groundwater protection and remediation.

If there are questions about our report, or points that need clarification, please give me a call at 574-7535.

LWM:air

Attachment: As Stated 


\section{Groundwater Program office Advisory Comittee \\ REPORT AND RECOMENDATIONS FOR 1995 \\ August 11, 1995}

The Groundwater Advisory Committee met at the Oak Ridge National Laboratory (ORNL) on July 26 and 27, 1995 to review the Lockheed Martin Energy Systems Groundwater Program Office (GWPO). The Advisory Committee consists of the following members:

- Dr. David A. Stephenson, President, South Pass Resources, Inc. Scottsdale, Arizona

- Or. William B. White, Professor of Geochemistry, The Pennsyivania State University, University Park, Pennsylvania

- Mr. L. W. McMahon, Program Manager, Y-12 Plant Environmental Management Department

During the two-day review, the Committee received inputs from the following:

- A short field tour of the Oak Ridge Reservation, particularly Union and Bear Creek Valleys and the K-25 site;

- Meetings with managers having responsibility within GWPO;

- Meetings with Technical Support Staff;

- Meetings with ORRHAGS Staff;

- Meetings with GWPO Coordinators/Site Managers; and

- Meetings with Environmental Compliance Division staff.

The observations, concerns, and recommendations presented in this report are based on an amalgamation of inputs received from these sources. The following comments are intended to be constructive and not to reflect negatively on the GWPO as a whole. The Committee's intent has been to identify areas where some action is recommended.

\section{Concerns Identifjed During 1995 Review}

The Advisory Committee found the GWPO involved in a company-wide reorganization of environmental restoration activities and in the throes of substantial budget reductions. Accordingly, the committee focused much of its attention on aspects of the reorganization that would impact the continued effectiveness of the GWPO. These aspects are discussed below.

1. GWPO's Place In The New Orqanizational Structure. Because the GWPO serves multiple clients, a matrix management system is appropriate. However, it is necessary that the GWPO manager be connected to line authority at a sufficiently high level to be able to defend budgets and ongoing tasks. It was not at all clear to the Committee that the proposed structure a) lows the GWPO to maintain a balanced response to its various "clients". 
2. A Task Order Framework for Project Management. Task orders usually apply to activities of specified scope and which persist for discrete and specified periods of time. It is not clear how this approach to program management will be applied to on-going site coordination activities that do not have well defined beginnings and ends. It is also unclear how task order management is to be applied to the ORRHAGS research programs. However the task order approach is deveioped, it is recommended that administrative time be a recognized task-order function.

3. Communication Within GWPO and Related Entities. One of the great strengths of the GWPO programs is the cross-communication that results from meetings with site Groundwater Coordinators and with ORRHAGS staff. It is important that this communication function not be lost when groundwater activities become part of a task order project.

4. Priority Setting and Research within the GWPO. These items appear as concerns in the 1994 Committee report and take on increased importance within the context of the new management and budget structures. Research within the GWPO is a mixture of science-oriented research and service work. The science-oriented research is carried out mainly by the ORRHAGS staff, and the service work is mainly performed by the site coordinators. The Committee was concerned to hear from the ORRHAGS staff that they felt that their work was very well integrated into overall GWPO goals and then to hear from site technical staff or site coordinators that the research activities often seem irrelevant. It is very important to the overall success of the GWPO that all components interact effectively and are mutualiy supportive.

The primary goals of the GWPO are utilitarian, and these goais need to be supported by first rate research. Although there is some very fine work underway, the Committee did not get a sense of priorities within the range of research projects. If the GWPO is indeed placed in a task order management framework, it becomes even more necessary that proposed research tasks be prioritized and that they have clearly defined objectives with respect to overall on-site compliance and remediation objectives.

The Committee sensed some uncertainty of objective within the research program itself. If the objectives of the various research projects are to be primarily supportive of the compliance and restoration activities, the appropriate product would be an internal report but the work should then be strongly coupled to the practical application. If the objective of the research projects is to be first rated science (and much of it is!) then the appropriate product would be publication in top tier peer-reviewed journals. There seems to be some sense that the work should be first class science but that the output would not go beyond the internal technical report. Judging from the lists of activities in the GWPO Annual Reports, the staff have been very effective at reporting their results at professional meetings but much less successful in carrying their work to the final step of journal publication, and to a direct application with on-site compliance and remediation objective. 
5. Outreach Function. It is strongiy recomended that the GWPO and ORHSP managers explore ways to advertise to other units within the Lockheed Martin Energy System Inc. matrix. The message should focus on the critical need for a strong, visible, viable overview function; and an understanding of the GWPO range of activities: to guarantee maintenance of an institutional memory, program guidance, senior review, monitoring of staff, and both inter-group and intra-group communications.

6. Relationship to Environmental Compliance. Any new management structure may tie the GWPO more closely to Environmental Restoration programs. It is imperative that strong ties be maintained with monitoring and compiiance programs. Currently a seemingly strong Tink exists between GWPO and Environmental Compliance (EC) staff. A viable linkage between GWPO and EC must be maintained in order to ensure a technical conscience as site characterization and remedial programs develop. It is strongly recommended that this objective not be overlooked in the course of on-going reorganization and task-order contracting.

7. Technical Support Staff Vacancy. It appears that Dick Ketelie is transferring to a coordinator's role at ORNL. If so, a new technical support staff person should be appointed for ORNL to ensure effective oneon-one relationships.

\section{Status of 1993 and 1994 Concerns}

The Advisory Comaittee reports for the 1993 and 1994 raised a variety of issues and concerns. Those issues and concerns that are stjil relevant are addressed below:

1. Staffing Levels. Concern was expressed in 1993 and 1994 about the level of staff support for site coordination and for research, especially in the area of carbonate rock (karst) hydrology. However, the site coordination function seems to be working well with the present assignment of single individuals to each of the five sites. The research side remains less than may be required. The Committee appreciates the budgetary constraints that pronibit the hiring of a karst hydrologist but the need for additional research on carbonate rock hydrology remains.

2. Water Balance Studies. In carbonate regions, an intimate interconnection exists between ground and surface water. In 19931994, it was recommended that water balance studies be initiated in the Bear Creek drainage to determine whether or not surface-water draining west of the $\mathrm{Y}-12$ Plant is lost to subsurface routes. The Committee was pleased to note that these investigations are now underway.

3. OREIS Develooment. Much attention was given to the status and function of the Oak Ridge Environmental Information System in previous comittee visits. The issue of OREIS was not raised by any of the groups that the Committee met with during the 1995 visit. 
4. Technical support to PAD and PORTS. With the establishment of one-onone GWPO coordinators for each site, the technical support aspect of GWPO's activities seems to be functioning very well. The GWPO coordinators were strongly supported by the site managers. The GWPO technical staff support was considered invaluabie, particularly by PAD and PORTS coordinators.

5. Vehicie and Space needs. These have been ongoing issues which were somewhat muted this year. The Committee notes that the promised new buildings are under construction. Quality office space for staff remains inadequate but the problem appears to be receiving attention.

6. Shipment of Samples Off-site. The 1994 Committee discussed the problem of regulatory barriers for off-site analysis of water samples. Apparently this problem persists and has no easy resolution. It seems like an unfortunate barrier to effective research.

\section{SUMMARY}

The Advisory Committee considers the GWPO to be integral to the scientific understanding of groundwater systems, groundwater protection, and environmental remediation within the DOE sites managed by Lockheed Martin Energy Systems. This belief is based in part on the assumption that containment of potential off-site contaminant migration is an extremely important function at the Oak Ridge Reservation, Paducah, and Portsmouth sites. Currently the GWPO provides a necessary function to assure that containment is achieved, and to adequately identify and develop remediation options. Furthermore, the maintenance of an "institutional memory," and a single overall technical oversight for both groundwater remedial investigations and on-going groundwater compliance monitoring are functions logically delegated to the GWPO. It is the recommendation of this committee that these functions not be ignored in the course of reorganizations and development of task order contracts. 
OAK RIDGE NATIONAL LABORATORY

MANAGED BY LOCKHEED MARTN ENERGY RESEARCH CORPORATION

FOR THE U.S. DEPARTMENT OF ENERGY

POST OFFCE BOX 2008

POST OFACE BOX 2008
OAK FIDGE TN $37231-6275$

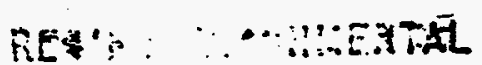

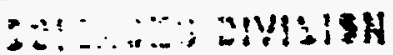

'96 OCT 3 PM 342
PHONE: (423) 574-6688

FAX: (423) $576-8739$

INTERNET: tek OOInt.gOV

Date: October 1, 1996

To: $\quad$ S. G. Hildebrand

cc/enc: G. K. Jacobs

From: $\quad$ F. C. Kornegay, 4500N, MS-6275, 4-6688

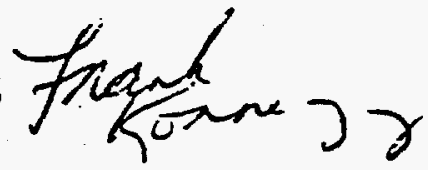

Subject: Groundwater Program Office (GWPO) Advisory Committee Report and Recommendations for 1996

Enclosed is the GWPO Advisory Committee Report and Recommendations for 1996. If you have any questions, please call me.

FCK:sco

Enclosure 


\title{
Groundwater Program Office Advisory Committee
}

\section{Report and Recommendations for 1996}

\author{
August 30, 1996
}

The Groundwater Program Office (GWPO) Advisory Committee met at the Oak Ridge National Laboratory (ORNL) on July 23-24, 1996. The Advisory Committee consists of the following members:

Dr. David A. Stephenson, President, South Pass Resources, Inc., Scottsdale, Arizona

Dr. William B. White, Professor of Geochemistry, The Pennsylvania State University, University Park, Pennsylvania

Mr. Frank C. Kornegay, Director, Safety and Health, Oak Ridge National Laboratory

During the review, the Committee:

Met with the research component of the GWPO (ORRHAGS).

Attended a quarterly meeting of the five site groundwater managers and the GWPO coordinators.

Met with DOE representative Paul Hofmann.

Met with Compliance Organization representatives Sarah Welch and John Murphy.

Participated in extensive discussions with GWPO managers Craig Rightmire and Dale Huff, plus Tom Row of ORNL Central Management.

\section{Observations and Principal Concerns}

Previous reports of the Advisory Committee have commented on the management structure of the Groundwater Program Office and a perceived lack of clear line responsibility to higher management. This year the Committee found the situation greatly exacerbated. Several factors are involved. One is the reorganization at the Corporate level into Lockheed Martin Energy Systems (LMES) and Lockheed Martin Energy Research (LMER). The responsibilities of the GWPO now cut across organizational lines that extend to the Sector level. A second factor is the new funding arrangements, in particular the loss of the "tax base" (Pool D) that has supported many GWPO activities. A third factor is the introduction of the Incentive Task Order (ITO) approach to project management. Each of these factors contributes to a considerable uncertainty within the GWPO regarding its mission, its staffing, and its funding.

Most deeply affected by the new management and funding arrangements is the research arm of the GWPO (ORRHAGS). As the emphasis within environmental restoration shifts more and more to specific cleanup activities and away from characterization and research, the role of the ORRHAGS scientists becomes more and more tenuous. 
As a result of funding limitations, the research staff is aiready dwindling. A post-doctoral person who carried an invaluable knowledge of the geology of the Oak Ridge Reservation (ORR) has already departed. It was estimated that 1.25 FTE have already been lost, leaving the present staff at 2.0 FTE-hardly a critical mass for a comprehensive research program.

The quality of scientific work performed by the ORRHAGS group continues to be high. Last year's committee emphasized the importance of carrying results past the ORNL report stage to their publication in the peer-reviewed scientific joumals. The research scientists responded to this recommendation, and it is noted that nine papers bave been prepared during the past year.

The site support function (ORHSP) continues to receive high marks. The activities on all five sites are appropriate and receive unqualified support from the site groundwater managers. This positive relationship should be highlighted as support for the continuance of the GWPO.

\section{Recommendations}

The GWPO serves a critical dual function of technical assistance and coordination of groundwater programs. It also plays an important role as a "corporate memory" for groundwater activities. It should be retained, but it must be retained with sufficient base support to permit it to function. The GWPO should be commissioned as the Reservation-wide coordination unit for all groundwater activities.

The GWPO should remain within the Environmental Sciences Division of ORNL and should resist pressures to become part of the Environmental Restoration (ER) organization. Within ER, there is no peer group, and the mission is more restrictive. The GWPO should be structured as an internal consulting organization, prepared to offer assistance to any part of the Lockheed Martin organization. By remaining in ORNL, it retains a measure of research mission to the extent that funding for these activities can be located. The GWPO should, however, retain an important role in ER activities as an independent source of technical review, for technical coordination with compliance, monitoring, and remediation activities, and for specific task-oriented research.

An alternative would be to elevate the GWPO into a Sector status, with lines of reporting to the Lockheed Martin Energy and Environment Sector. That may better enable the GWPO to also coordinate groundwater activities at other national facilities.

The site support activity is successful, working well, and should be retained in more or less in present form. This type of activity does not lend itself well to the ITO type of management. It is suggested that there always be an active interplay between site managers and their respective ORHSP and other team members during the quarterly meetings. The recent meeting, attended by the Committee, did not display much active discussion, although it is recognized that time available was limited.

It is important to consider retaining the research arm of the GWPO. However, it seems unlikely that the present arrangement of unstructured research can survive. Within the context of ITO management, an effort should be made to identify fundable projects anywhere within the DOE or LMER organization. Specific research can be structured along ITO guidelines. ORRHAGS efforts, if able to continue, should move into a more applied emphasis.

Contrary to what appears to be a perception by some that no further research is needed on the ORR, important problems that have immediate impact on environmental restoration activities and would have significant relationships to investigation of any real or potential off-site movement of quality degraded groundwater remain. Examples are: 
An updated and greatly improved conceptual model for the hydrogeology of the ORR is now possible and should be developed.

Potential exit pathways in the Maynardville Limestone have been identified, but the detailed hydrologic behavior of these pathways is unknown and are ripe for investigation.

The GWPO needs to "evangelize" and gain greater visibility. In particular, the GWPO should continue to highlight a summary of its accomplishments with emphasis on activities that have resulted in definable cost savings. The GWPO should also consider aggressively pursuing or creating opportunities to be active at other national laboratory sites.

Perhaps the most significant recommendation is that the GWPO staff increase communication at all levels. The type of discussions, for example, that occurred between the GWPO leaders and Tom Row seemed to generate positive feedback on planning of future activities. It is probably realistic to state that day-to-day activities oftentimes negate opportunities to communicate with key individuals outside of the GWPO. Nevertheless, opportunities for communication should be aggressively pursued. 


\section{INTERNAL DISTRIBUTION}

1. F. Anderson, X-7725, MS-7615

2. M. Belvin, $4500 \mathrm{~N}, \mathrm{MS}-6269$

3. W.D. Brickeen, 7078-D, MS-6402

4. F. Bullock, X-7725, MS-7603

5. D. Cope, $4007, \mathrm{MS}-6075$

6. K. Cook, K1225, MS-7294

7. J. H. Cushman, 1059, MS-6422

8. R. K. Davis, 1509, MS-6400

9. A. F. Diefendorf, 1509, MS-6400

10. W. E. Doll, 1509, MS-6400

11. J. Donnelly, 9114, MS-SE32

12. J. W. Douthitt, KEVIL, MS-0000

13. R. C. Durfee, 4500 N, MS-6274

14. T. O. Early, 1509 , MS- 6400

15. J. M. Forstrom, 1000 , MS-6296

16. D. E. Fowler, 1505, MS-6035

17. S. B. Garland, K-1225, MS-7294

18. J. P. Gwo, 4500-N, MS-6203

19. C. S. Haase, $9883-58$, MS- 8247

20. S. G. Hildebrand, 1505, MS-6037

21-25: (5) D. D. Huff, 1509, MS-6400

26. G. K. Jacobs, 1505 , MS-6036

27. P. M. Jardine, 1505 , MS- 6038

28. S. Jones, $9720-20$, MS-8085

29. P. Kancircuk, 1507, MS-6407
30. R. H. Ketelle, 4500 N, MS-6185

31. A. J. Kuhaida, 7078-A, MS-6402

32. S.Y. Lee, 1505 , MS-6038

33. J. M. Loar, 1505, MS-6036

34. J. F. McCarthy, 1505, MS-6036

35. G. Moline, 1509, MS-6400

36. C. A. Motley, K-1330, MS-7298

37. T. E. Myrick, 4500 , MS-6253

38. P. D. Parr, 1505 , MS-6038

39. D. E. Reichle, 4500 N, MS-6253

40-44. (5) C. T. Rightmire, MS-6400

45. S. D. Shriner, 1505 , MS-6038

46. E. D. Smith, 1505 , MS-6038

47. P. L. Stafford, 1505 , MS-6036

48. J. R. Trabalka, 4500-N, MS-6180

49. K. Turner, K1330, MS-7298

50. S. VanderHoven, 1509 , MS-6400

51. D. B. Watson, 1509 , MS-6400

52. S. L. Winters, X-7725, MS-7603

53. T. Zondlo, 1509, MS-6400

54. Central Research Library

55-69. (15) ESD Library

70-71. (2) Laboratory Records Department

72. Laboratory Records, ORNL-RC

\section{EXTERNAL DISTRIBUTION}

73. M. Broido, Acting Director, Environmental Sciences Division, ER-74, Department of Energy, 19901 Germantown Road, Germantown, Maryland 20874

74. B. A. Bryan, USGS, 1820 Midpark Drive, Knoxville, Tennessee 37921

75. E. G. Cumesty, ORNL Site Manager, Department of Energy, Oak Ridge National Laboratory, P.O. Box 2008, Oak Ridge, Tennessee 37831-6269

76. N. H. Cutshall, ORNL, 2800 Middlebrook Road, Suite 102, Trevion II, Germantown, Maryland 20874

77. R. D. Hatcher, University of Tennessee, Department of Geological Sciences, Knoxville, Tennessee 37996 
78. P. Hofmann, Department of Energy, Oak Ridge Operations Office, P.O. Box 2001, Oak Ridge, Tennessee 37831

79. P. J. Lemiszki, University of Tennessee, Department of Geological Sciences, Knoxville, Tennessee 37996

80. Michael C. McCracken, Director, Office of U.S. Global Change Research Program, Code YS-1, 300 E Street, SW, Washington, DC 20546

81. L. D. McKay, University of Tennessee, Department of Geological Sciences, Knoxville, Tennessee 37996

82. H. Y. McSween, University of Tennessee, Department of Geological Sciences, Knoxville, Tennessee 37996

83. H. C. Mattraw, Jr., USGS, 640 Grassmere Park, Suite 100, Nashville, Tennessee 37211

84. Ronit Nativ, Faculty of Agriculture, Lubell Building, Office 34, Hertzel Street, Rohovot, Israel 76100

85. A. Patrinos, Associate Director, Office of Health and Environmental Research, ER-70, Department of Energy, Germantown, Maryland 20874

86. G. Reed, University of Tennessee, Department of Geological Sciences, Knoxville, Tennessee 37996

87. S. P. Riddle, Department of Energy, Oak Ridge Operations Office, P.O. Box 2001, Oak Ridge, Tennessee 37831

88. W. E. Sanford, Department of Earth Resources, Colorado State University, Ft. Collins, Colorado 80523-1482

89. R. Skinner, Department of Energy, Oak Ridge Operations Office, P.O. Box 2001, Oak Ridge, Tennessee 37831

90. R. C. Sleeman, Department of Energy, Oak Ridge Operations Office, P.O. Box 2001, Oak Ridge, Tennessee 37831

91. J. L. Smoot, University of Tennessee, Department of Geological Sciences, Knoxville, Tennessee 37996

92. B. P. Spalding, ORNL, 2597 Three-quarter Road, Grand Junction, Colorado 81502

93. D. K. Solomon, Department of Geology and Geophysics, 717 W. C. Browning Building, Salt Lake City, Utah 84112-1183 
94. J. T. Sweeney, Department of Energy, Oak Ridge Operations Office, P.O. Box 2001, Oak Ridge, Tennessee 37831

95. L. E. Toran, Department of Geology, Temple University, Philadelphia, Pennsylvania 19122

96. D. A. Webster, USGS, 640 Grassmere Park, Suite 100, Nashville, Tennessee 37211

97. Office of Assistant Manager for Energy Research and Development, U.S. Department of Energy Oak Ridge Operations, P.O. Box 2001, Oak Ridge, Tennessee 37831-8600

98-99. (2) Office of Scientific and Technical Information, P.O. Box 62, Oak Ridge, Tennessee 37831

Please do not forward or discard this document.

If this address is not correct for the designated addressee, please return the document to:

Oak Ridge National Laboratory, ESD/GWPO

P.O. Box 2008

Building 1509, MS-6400

Oak Ridge, Tennessee 37831-6400 